Review Article

\title{
Insights into the Role of Oxidative Stress in Ovarian Cancer
}

\author{
Dan-Ni Ding $\mathbb{D},{ }^{1}$ Liang-Zhen Xie $\mathbb{C D}^{1,2}$ Ying Shen $\mathbb{D},{ }^{1}$ Jia Li $\mathbb{D},{ }^{1}$ Ying Guo $\mathbb{D},{ }^{2}$ Yang Fu $\mathbb{D},{ }^{2}$ \\ Fang-Yuan Liu $\mathbb{D}^{1}$, and Feng-Juan Han $\mathbb{D}^{2}$ \\ ${ }^{1}$ Department of Obstetrics and Gynecology, Heilongjiang University of Chinese Medicine, Harbin 150040, China \\ ${ }^{2}$ Department of Obstetrics and Gynecology, The First Affiliated Hospital of Heilongiiang University of Chinese Medicine, \\ Harbin 150040, China
}

Correspondence should be addressed to Fang-Yuan Liu; fangyuanliu2021@163.com

and Feng-Juan Han; hanfengjuan2004@163.com

Received 8 May 2021; Accepted 7 September 2021; Published 7 October 2021

Academic Editor: Maria Isaguliants

Copyright ( 92021 Dan-Ni Ding et al. This is an open access article distributed under the Creative Commons Attribution License, which permits unrestricted use, distribution, and reproduction in any medium, provided the original work is properly cited.

Oxidative stress (OS) arises when the body is subjected to harmful endogenous or exogenous factors that overwhelm the antioxidant system. There is increasing evidence that OS is involved in a number of diseases, including ovarian cancer (OC). OC is the most lethal gynecological malignancy, and risk factors include genetic factors, age, infertility, nulliparity, microbial infections, obesity, smoking, etc. OS can promote the proliferation, metastasis, and therapy resistance of OC, while high levels of OS have cytotoxic effects and induce apoptosis in OC cells. This review focuses on the relationship between OS and the development of OC from four aspects: genetic alterations, signaling pathways, transcription factors, and the tumor microenvironment. Furthermore, strategies to target aberrant OS in OC are summarized and discussed, with a view to providing new ideas for clinical treatment.

\section{Introduction}

Ovarian cancer (OC) is the third most common cancer among women, with 290,000 women diagnosed and 180,000 dying every year globally, and OC is the most lethal gynecological cancer with a five-year survival below $45 \%$ [1, 2]. Currently, OC is divided into type I and type II tumors according to the clinical, genetic, and histopathological factors in the revised ovarian carcinogenesis model [3]. Type I tumors develop from benign extraovarian precursor lesions that are present in the ovary, and these tumors are mostly confined to the ovary and have a good prognosis, accounting for only $10 \%$ of OC-related deaths. Type II tumors are generally thought to develop from serous tubal intraepithelial carcinoma based on both shared TP53 mutations and integrated molecular analyses [4]. They are more aggressive, resulting in $90 \%$ of the deaths from OC, of which highgrade serous carcinoma (HGSC) is by far the most common form of diagnosis, resulting in $70-80 \%$ of deaths from OC $[5,6]$. Understanding the etiology of OC is of great significance for its prevention and treatment. The current treat- ment for OC includes surgical resection, chemotherapy, neoadjuvant chemotherapy, radiotherapy, and immunotherapy $[7,8]$. However, more than $50 \%$ of OC patients eventually relapse and suffer from late metastasis, and secondary adverse reactions and drug resistance pose major challenges to treating OC [9].

Oxidative stress (OS) arises when there is an imbalance between the production of free radicals and reactive metabolites (so-called prooxidants, including reactive oxygen and nitrogen species) and intrinsic antioxidant defenses. This imbalance leads to damage of biological molecules and tissues and has the potential to impact on the whole organism $[10,11]$. Reactive oxygen species (ROS) are represented by free radicals and nonfree radical oxygen-containing molecules, including superoxide anions $\left(\mathrm{O}_{2}{ }^{-}\right)$, hydrogen peroxides $\left(\mathrm{H}_{2} \mathrm{O}_{2}\right)$, singlet oxygens $\left({ }^{1} \mathrm{O}_{2}\right)$, and hydroxyl radicals $(\mathrm{OH} \cdot)[12,13]$. Reactive nitrogen species (RNS) include nitric oxide (NO.) and peroxynitrite anions $\left(\mathrm{ONOO}^{-}\right)$[14] (Figure 1). The generation of ROS and RNS is dependent on both enzymatic and nonenzymatic reactions. Enzymatic reactions mainly involve nicotinamide adenine dinucleotide 


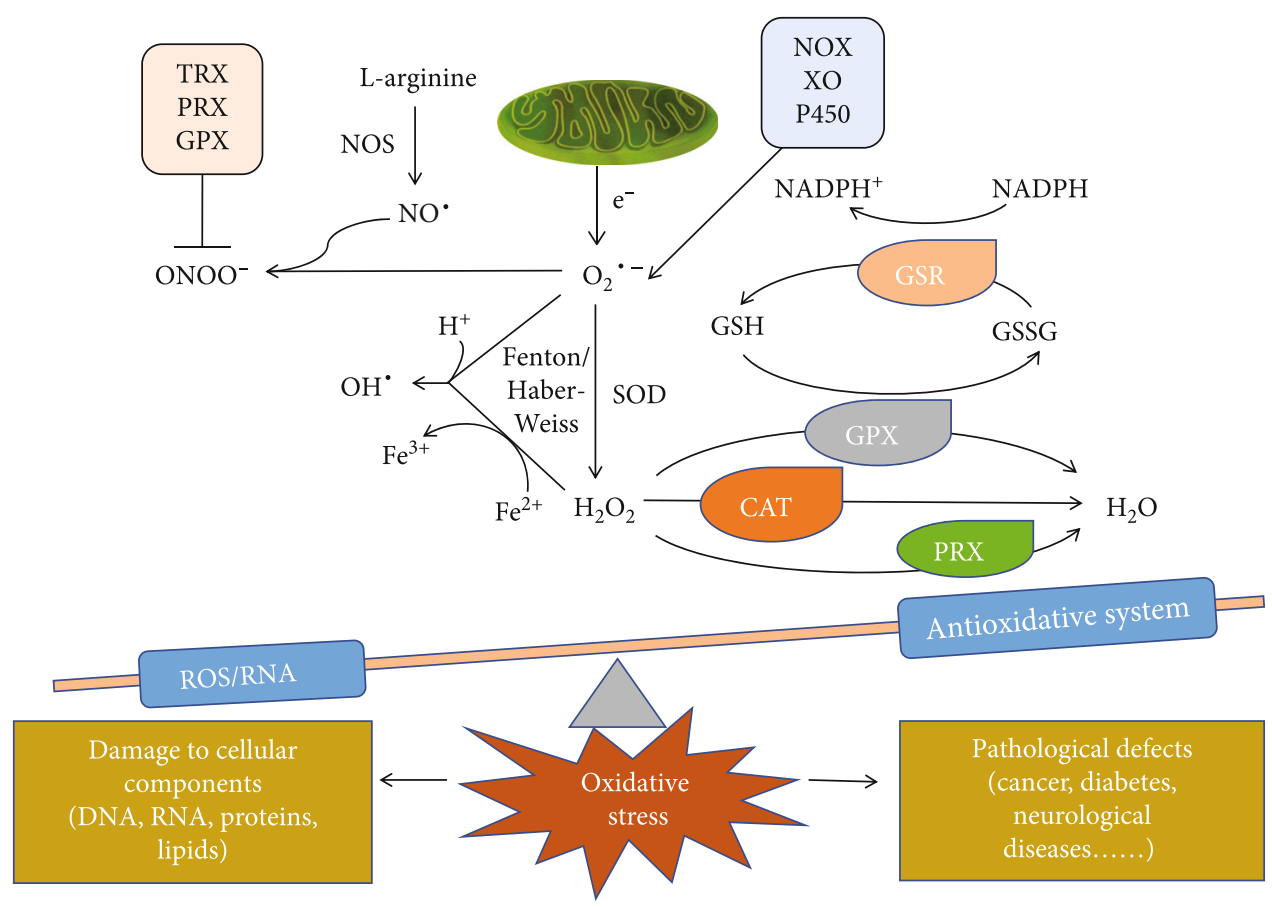

Figure 1: The major oxidative and antioxidant systems. Both electron leakage from the mitochondria and enzymatic activity of the oxidase system, as represented by NOX, XO, and cytochrome P450, produce $\mathrm{O}_{2} .^{-}$. SOD converts $\mathrm{O}_{2} .^{-}$into $\mathrm{H}_{2} \mathrm{O}_{2}$ [233], and in the presence of reducing transition metals, such as ferrous ions, $\mathrm{H}_{2} \mathrm{O}_{2}$ is converted into highly active $\mathrm{OH}$. by the Fenton or Haber-Weiss reaction [26]. $\mathrm{H}_{2} \mathrm{O}_{2}$ is converted into $\mathrm{H}_{2} \mathrm{O}$ by CAT, PRX, and GPX. In the GPX reaction, GSH is oxidized to GSSG (glutathione disulfide), which can be converted back to GSH by GSR during NADPH consumption [15]. L-Arginine is converted to NO- under the catalysis of nitric oxide synthase (NOS), which reacts with $\mathrm{O}_{2} .^{-}$to form $\mathrm{ONOO}^{-}$[234]. TRX, PRX, and GPX can inhibit ONOO ${ }^{-}$generation [24]. Each ROS has different physical and chemical properties and half-lives. Among these, $\mathrm{OH}$. has the strongest oxidizing property, followed by $\mathrm{O}_{2} \cdot{ }^{-}$, while $\mathrm{H}_{2} \mathrm{O}_{2}$ is relatively weak. $\mathrm{H}_{2} \mathrm{O}_{2}$ and $\mathrm{NO}$. also play essential roles as signaling molecules [31].

(NADPH) oxidase (NOX), xanthine oxidase $(\mathrm{XO})$, peroxidase, and the cytochrome P450 system [15-17], while nonenzymatic reactions, i.e., electron leakage from the mitochondrial respiratory chain, are the main source of ROS [18]. To avoid OS, cells possess a series of nonenzymatic and enzymatic antioxidant defense systems. The nonenzymatic defense system includes flavonoids, vitamins (A, C, and $\mathrm{E}$ ), and glutathione (GSH) $[19,20]$, while the enzymatic antioxidant system consists of superoxide dismutase (SOD), catalase (CAT), glutathione peroxidase (GPX), glutathione reductase (GSR), glutathione S-transferases (GST), peroxiredoxin (PRX), and thioredoxin (TRX) [21-25] (Figure 1). In healthy organisms, ROS and RNS are normal by-products of cellular metabolism and participate in the transduction of different signaling pathways, and the antioxidant defense system will quickly remove them before they cause damage to cellular structure and function $[22,26]$. However, many endogenous factors (mental stress, inflammation, various enzymatic systems, etc.) and exogenous factors (ultraviolet radiation, ionizing radiation, air pollution, etc.) can induce excessive production of ROS and RNS in cells [27-29]. This heightened production of oxidants can overwhelm the body's antioxidant defense system leading to a state of OS, which in turn leads to irreversible oxidative damage to proteins, lipids, and nucleic acids [30]. Such damage interferes with key cellular functions, and this is closely related to the occurrence and development of cancer, diabetes, and cardio- vascular and nervous system diseases, to name just a few [31, 32] (Figure 1).

OS has been widely confirmed to play a dual role in the pathogenesis of cancer $[11,33]$. On the one hand, ROS/RNS can promote molecular genetic changes that lead to tumor initiation, growth, and development as well as to therapeutic resistance [34, 35]. On the other hand, long-term elevated ROS/RNS levels have cytotoxic effects and can induce the activation of apoptotic pathways $[35,36]$. It is well known that cancer cells contain higher levels of reactive molecules that maintain the cellular phenotype and high proliferation rate, and tumor cells must find ways to optimize ROSdriven proliferation while avoiding ROS thresholds that trigger senescence, apoptosis, or ferroptosis [37, 38]. Several studies on OC have confirmed this and have shown upregulated responses to OS in OC cells. For example, NOX, inducible nitric oxide synthase (iNOS) [39-41], and SOD [42, 43] are overexpressed in OC compared with normal tissues, and GSTs have been reported to be overexpressed in human malignancies and to be associated with tumor progression and drug resistance [44]. OS triggers cancer cells to produce lactic acid by glycolysis rather than oxidative phosphorylation, even under aerobic conditions, which is referred to as aerobic glycolysis or the Warburg effect [45]. The Warburg effect has been used to detect and monitor tumor progression in the clinic using positron emission tomography to detect highly glycolytic regions in the body by measuring 
$2-\left[{ }^{18} \mathrm{~F}\right]$ fluoro-2-deoxy-D-glucose (a glucose analogue concentrated in highly proliferative tumorigenic tissues) [46]. Iron and its metabolites promote the generation of ROS via the Fenton reaction, and these ROS induce DNA damage thus leading to carcinogenesis. For example, when chocolate cysts form, the ovary contains old blood with excessive iron, which may increase the risk of malignant transformation of endometriosis into ovarian clear cell carcinomas [47]. At the same time, when cells are moderately exposed to nontoxic doses of $\mathrm{H}_{2} \mathrm{O}_{2}$, glucose-6-phosphate dehydrogenase (G6PD) is activated, which leads to a switch in glucose metabolism from glycolysis to the pentose phosphate pathway (PPP) and nucleotide synthesis. This approach avoids exposing tumor cells to OS due to the production of ROS and provides a survival advantage for the development of cancer $[48,49]$. In addition, NADPH produced by the PPP is used for reductive biosynthetic reactions in cells, which enhances the GSH and TRX-based antioxidant systems and maintains ROS levels in a state of dynamic equilibrium [50-53]. Cells adapt to OS through metabolic reprogramming in the short term while genetic reprogramming provides long-term adaptation [54-56]. OS can regulate the redox state of tumor cells by regulating gene expression or activating different transcription factors, such as activating protein $1, \mathrm{HIF}-1 \alpha$, heat shock factor $1, \mathrm{NF}-\kappa \mathrm{B}, \mathrm{Nrf} 2$, and the tumor inhibitor p53 [11, 57]. Additionally, ROS also interact with signaling molecules such as mitogen-activated protein kinase (MAPK), phosphatidylinositol 3-kinase (PI3K), phosphatase and tensin homolog (PTEN), and protein tyrosine phosphatase (PTP) by targeting reactive cysteine residues in proteins to activate a variety of cellular processes, thus regulating cell proliferation, differentiation, migration, and apoptosis [58-61].

Many factors are involved in OC, including genetic factors, age, infertility, nulliparity, microbial infections, obesity, and smoking $[7,8]$. A number of studies have been conducted on the role of OS in the development of OC [16, 62-66], and the strong association between OS and OC is gradually becoming a hot topic of interest. This review updates the relevant literature and focuses on teasing out the effects of OS on OC from different perspectives. In addition, we comprehensively analyze the interaction between OS and genetic alterations, different signaling pathways and transcription factors, and different components of the tumor microenvironment (TME) to further explore the role of OS in the pathogenesis and treatment of OC.

\section{OS-Related Pathogenesis in OC}

OS leads to the development of OC through four aspects: genetic alterations, signaling pathways, transcription factors, and the TME (Figure 2).

2.1. OS-Mediated Genetic Alterations in OC. OC can be triggered through OS-mediated genetic alterations such as oxidative damage of nuclear DNA and mitochondrial DNA (mtDNA), DNA hypomethylation, and abnormal expression of microRNA. The specific mechanisms are as follows.
DNA damage and genetic instability caused by OS play a crucial role in the occurrence and development of OC [67, 68]. $\mathrm{H}_{2} \mathrm{O}_{2}$ and the hydroxyl radicals generated by the Fenton reaction have been shown to promote the transferrin- (Tf-) TfR1 axis, which induces DNA double-strand breaks in epithelial cells of the fallopian tube, which promotes the progression of OC [69]. The most common product of DNA oxidative damage is 8 -hydroxy- $2^{\prime}$-deoxyguanosine (8-OHdG), which is formed by guanine oxidation [70], and it is usually used as a biomarker of DNA damage as well as for assessing the risk associated with cancer progression [71-73]. In addition, 8-OHdG can induce C:G to A:T transformations, which are the most important somatic mutations in OC, breast cancer, lung cancer, and gastric cancer [74]. Also, about half of all patients with OC have abnormal homologous recombination repair (HRR) [8]. A recent study showed that inhibition or depletion of RAD51, a key protein involved in HRR, can lead to OS and increased DNA oxidative damage in OC, and this reflects the involvement of HRR in redox state regulation in OC [75].

mtDNA is more susceptible to oxidative damage than nuclear DNA because mitochondria house the electron transport chain that produces large amounts of ROS [76], and mitochondria lack effective DNA repair mechanisms [77]. mtDNA mutations have been reported in various cancers, including OC [78-81], and studies have shown that many chemical carcinogens preferentially bind to mtDNA rather than nuclear DNA [82]. In addition, damage to nuclear DNA can trigger mitochondrial reactions, while the increase in ROS in mitochondria can aggravate nuclear DNA damage $[83,84]$; therefore, there may be a "vicious circle" between OS, DNA damage, and cancer development [85]. A correlation between mtDNA mutations and response to therapy in OC has also been reported. HGSC patients with heteroplasmic pathogenic mtDNA somatic mutations were found to have a higher incidence of platinum resistance and disease relapse compared to patients without pathogenic mtDNA somatic mutations ( $80 \%$ vs. $16.7 \%, p=0.035)$, and the phenomenon of accumulation of oxidative damagederived $\mathrm{G}>\mathrm{T}$ and $\mathrm{A}>\mathrm{C}$ somatic mutations in the tumor samples indicated that the tumor cells were exposed to OS [86]. Another study suggested that disruptive mtDNA mutations may be used as adjuvant prognostic molecular markers [87].

DNA methylation is one of the primary epigenetic mechanisms for regulating gene expression, and DNA hypomethylation has been reported to be associated with the initiation and progression of various cancers [88]. DNA methylation involves the covalent bonding of a methyl group to the 5th carbon position of the cytosine of the genomic CpG dinucleotide by DNA methyltransferase [89], and this process is inhibited by ROS, thus leading to DNA hypomethylation [90-92]. The change in DNA methylation is an early event in OC [93], and DNA hypomethylation has been shown to contribute to the high expression of SLC4A11 (a solute-linked cotransporter), which is related to the poor prognosis of OC caused by OS [94].

MicroRNAs (miRNAs) also play roles in the pathogenesis of OC $[65,95]$. miRNAs are small noncoding RNAs that 


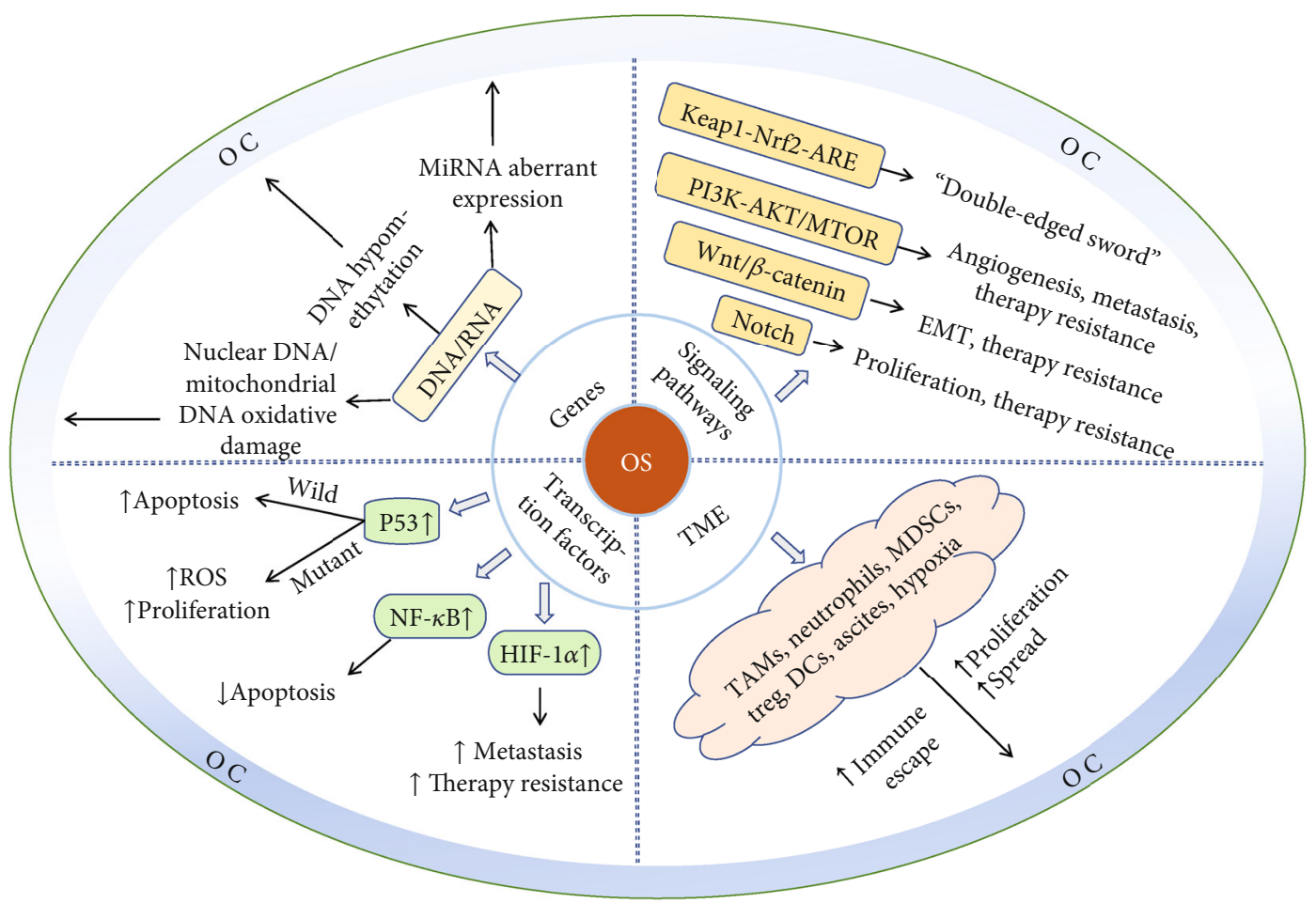

FIGURE 2: OS-related pathogenesis in OC.

participate in the regulation of posttranscriptional gene expression by inducing mRNA degradation or inhibiting translation [96]. In addition, miRNAs are considered to be important mediators of the immune system, to be involved in inflammatory reactions, and to be closely related to the progress and treatment of diseases [97]. Several studies have demonstrated that OS can increase the sensitivity of OC cells to paclitaxel and promote the mesenchymal-epithelial transition by stimulating the overexpression of miR-141 and miR-200s [98, 99].

2.2. OS-Mediated Alterations of Signaling Pathways in OC. Many studies have confirmed the important role of redox modification of signaling pathways in the pathogenesis of OC, including the Keap1-Nrf2-ARE, PI3K/AKT/mTOR, $\mathrm{Wnt} / \beta$-catenin, and Notch pathways [100-103].

2.2.1. Keap1-Nrf2-ARE Signaling Pathway. The Keap1-Nrf2ARE signaling pathway is one of the most important pathways through which cells respond to OS, and it has attracted attention due to its ability to regulate a broad range of antioxidant and detoxification genes [31, 104]. Nuclear factor E2-related factor 2 (Nrf2), which is at the center of this pathway, regulates the transcription of genes that encode various detoxifying enzymes and antioxidant proteins [105]. Under homeostatic conditions, Nrf2 is usually localized in the cytoplasm, where it binds to the inhibitor Kelch-like ECHassociated protein 1 (Keap1). Keap1 is an adaptor protein for the Cullin3-dependent E3 ubiquitin ligase, which mediates the ubiquitination and subsequent degradation $\mathrm{Nrf} 2$ in order to maintain basal levels of the protein [106, 107] (Figure 3). When cells are exposed to OS, the cysteine residues of Keap1 are oxidized, which causes Nrf2 to dissociate from the Keap1 complex and translocate into the nucleus. There it forms a heterodimer with the Maf (musculoaponeurotic fibrosarcoma) protein, which then binds to ARE, the first antioxidant response element to be identified. Thus, Nrf2-regulated antioxidant gene transcription can be activated to exert an antioxidant effect [108, 109] (Figure 3). The activation of the Nrf2 pathway is considered to be a double-edged sword in OC $[104,110,111]$ (Figure 3). On the one hand, the Nrf2 pathway can maintain the stability of the normal ovarian cell environment and genome to prevent carcinogenesis induced by OS [112]. On the other hand, the Nrf2 pathway protects OC cells from oxidative damage $[113,114]$ and helps them cope with various cytotoxic drugs, thus enhancing the invasive ability and chemotherapy resistance of OC $[110,115]$.

The chemotherapy resistance of OC cells is related to mutations within highly conserved domains of the Keapl gene [116] and to the activation of downstream genes of the Nrf2 pathway [117]. The downstream antioxidant proteins of the Nrf2 pathway mediate detoxification through glutathione coupling and participate in ATP-dependent drug efflux, which may be one of the mechanisms of drug resistance in OC cells [107]. In addition, inhibiting the production of proteasomes promotes the translocation of $\mathrm{Nrf} 2$ into the nucleus via the Keap1/Nrf2 pathway, resulting in drug resistance in OC cells. Nrf2 and peroxisome proliferator-activated receptor- $\gamma$ coactivator $1 \alpha$ (PGC1 $\alpha)$ can synergistically regulate antioxidant functions and mitochondrial functions, thus regulating the maintenance of proteasome activity and affecting the sensitivity of OC cells to chemotherapy agents [101]. 


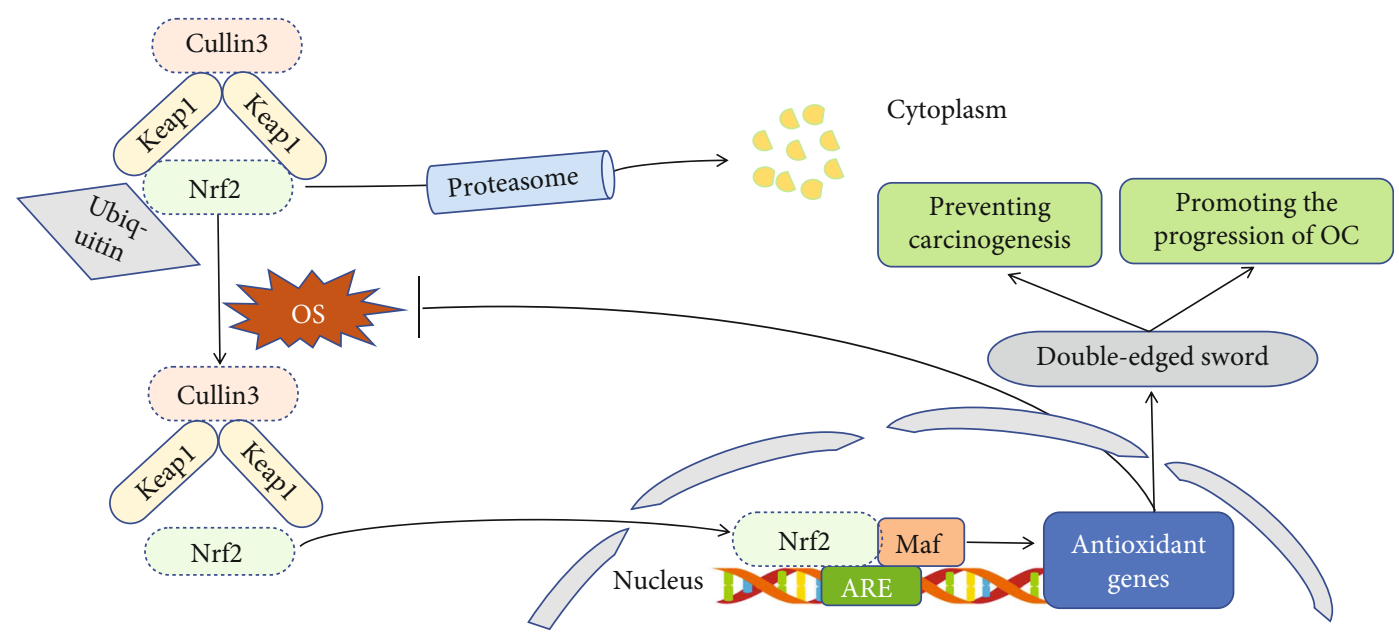

FIGURE 3: Transduction mechanism of the OS-mediated Keap1-Nrf2-ARE signaling pathway in OC. Under physiological conditions, Nrf2 is retained in the cytoplasm by Keap1. Keap1 binds Nrf2 to the Cullin3-dependent E3 ubiquitin ligase complex, which promotes the ubiquitination and subsequent proteasome degradation of Nrf2 [106, 107]. Under conditions of OS, the cysteine residues exposed on the surface of Keap1 are oxidized, which causes Nrf2 to dissociate from Keap1, translocate to the nucleus, form a heterodimer with Maf, and then bind with ARE, thereby transcriptionally activating Nrf2-regulated antioxidant gene expression and inhibiting OS [108, 109]. The activation of the Nrf2 pathway is a double-edged sword in OC, and it maintains the stability of the normal ovarian cell environment and genome in order to prevent OS-induced carcinogenesis [112], while it also protects tumor cells from OS thus enhancing the invasion and chemoresistance of OC $[110,115]$.

Recently, the Keap1-Nrf2-ARE pathway has been shown to play an important role in the prognosis of OC. Cho et al. detected the expression of Nrf2 and Keap1 in 100 cases of epithelial ovarian cancer (EOC) tissues by immunohistochemistry and followed up all patients for a mean of 55.3 months. They found that Nrf2 was overexpressed in the cytoplasm of OC cells. Further survival analysis showed that high Keap1 expression predicted better overall survival and was an independent prognostic factor. Specifically, high levels of Keap1 in the cytoplasm can inhibit the nuclear translocation and enhance the negative feedback control of Nrf2, thereby inhibiting the survival of OC cells [118].

\subsubsection{PI3K/AKT/mTOR Signaling Pathway. The PI3K/protein} kinase $\mathrm{B} / \mathrm{mammalian}$ target of rapamycin (PI3K/AKT/mTOR) signaling pathway plays a central role in the proliferation, migration, and chemoresistance of OC [119-122], and the specific transduction mechanism is shown in Figure 4. ROS can inhibit the activity of PTP and PTEN by oxidizing cysteine residues, thus activating the $\mathrm{PI} 3 \mathrm{~K} / \mathrm{AKT} / \mathrm{mTOR}$ pathway [123-125] (Figure 4). Moreover, the expression of PTEN was reported to be decreased in 104 of 151 analyzed EOC samples [126]. OS facilitates the growth and metastasis of OC by activating the $\mathrm{PI} 3 \mathrm{~K} / \mathrm{AKT} / \mathrm{mTOR}$ pathway in order to increase the expression of vascular endothelial growth factor (VEGF) [127] and to promote de novo fatty acid and cholesterol biosynthesis [100]. In addition, NO can protect OC cells from apoptosis and can enhance drug resistance by activating the $\mathrm{PI} 3 \mathrm{~K} / \mathrm{AKT} / \mathrm{mTOR}$ pathway [128]. Interestingly, another study on OC showed a contrasting phenomenon in which ROS mediated apoptosis by inhibiting the PI3K/AKT/mTOR signaling pathway [129], which was related to the concentration of ROS and confirmed the dual role of OS in cancer.
2.2.3. Wnt/ $\beta$-Catenin Signaling Pathway. Another important signaling pathway in $\mathrm{OC}$ is $\mathrm{Wnt} / \beta$-catenin, which plays a role in metastasis and therapy resistance [130-133]. Recent studies have also shown that it contributes to immune evasion of OC $[134,135]$. NOX1-derived ROS have been reported to stimulate the $\mathrm{Wnt} / \beta$-catenin pathway by oxidizing and inactivating nucleoredoxin (a redox-sensitive regulatory protein that negatively regulates the Wnt pathway by interacting with the Disheveled protein), thus promoting tumor cell proliferation [136] (Figure 5). As shown in Figure 5, in the absence of canonical Wnt ligands, the level of intracellular $\beta$-catenin is regulated by the polyprotein "destruction complex" [137]. CK1 and unphosphorylated GSK3 $\beta$ phosphorylate $\beta$-catenin and target it for degradation [133]. The PI3K/AKT pathway is activated by ROS and phosphorylates GSK3 $\beta$, thus inhibiting its ability to phosphorylate and degrade $\beta$-catenin $[138,139]$ (Figure 5). Moreover, phosphorylated GSK3 $\beta$ is often found in OC [133]. A study showed that tankyrase (an oncogenic regulator of OC cell proliferation) promotes aerobic glycolysis of OC cells by stimulating the $\mathrm{Wnt} / \beta$-catenin/Snail pathway [102]. Taken together, these results indicate that there is a bidirectional regulation between the $\mathrm{Wnt} / \beta$-catenin pathway and the redox state of OC cells, and the interactions of these regulatory mechanisms are involved in the pathogenesis of OC.

Many reports on the invasive properties of OC have shown that the activation of epithelial-mesenchymal transition (EMT) is critical for the acquisition of a malignant phenotype in OC, especially in HGSC [140, 141]. OC cells undergoing EMT have stem cell-like properties that enable them to spread and metastasize [133]. The $\mathrm{Wnt} / \beta$-catenin pathway is considered to be one of the main signaling pathways involved in EMT, and it plays a key role in the 


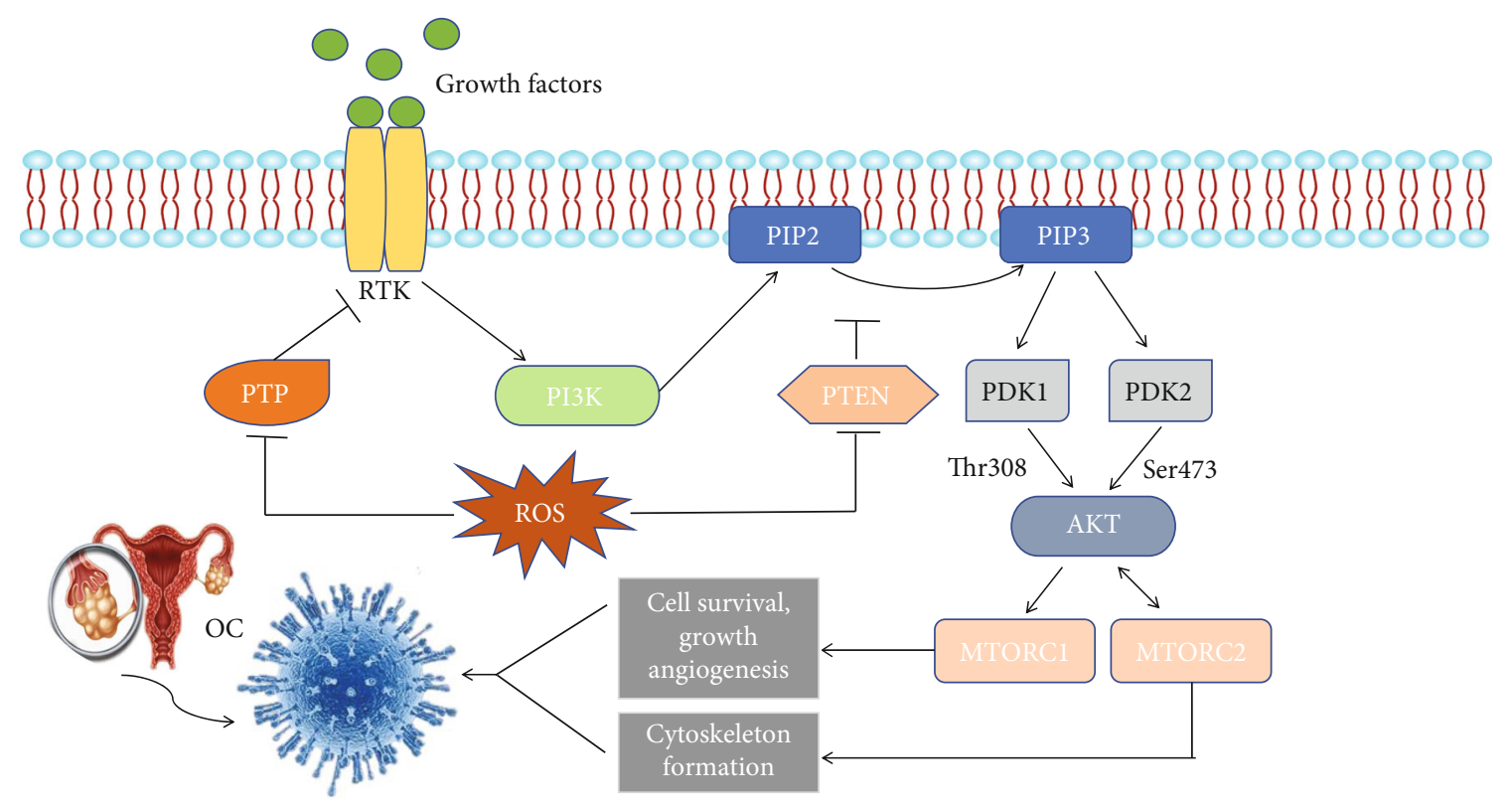

FIGURE 4: Transduction mechanism of the OS-mediated PI3K/AKT/mTOR signaling pathway in OC. Growth factors interact with receptor tyrosine kinase (RTK) leading to PI3K activation, which can be inhibited by PTP [136, 235]. Fully activated PI3K phosphorylates phosphatidylinositol bisphosphate (PIP2) to phosphatidylinositol trisphosphate (PIP3). This conversion results in the activation of AKT by phosphorylation of its kinase domain (Thr308) by PDK1 and phosphorylation of its C-terminal domain (Ser473) by PDK2. AKT can further activate mTOR, which includes mTOR complex 1 (mTORC1) and mTORC2. Activation of mTORC1 leads to cell survival, growth, and angiogenesis, while mTORC2 has been implicated in cytoskeleton formation and cell survival [235, 236]. PTEN reverses the effects of PI3K by dephosphorylating PIP3 [236]. ROS can inhibit the activity of PTP and PTEN by oxidizing cysteine residues, thus activating the PI3K/AKT/mTOR pathway [123-125] leading to the proliferation, migration, and chemotherapy resistance in OC.

regulation and maintenance of OC stemness [142-144]. In addition, the $\mathrm{Wnt} / \beta$-catenin signaling pathway is involved in the remodeling of the extracellular matrix in $\mathrm{OC}$, which may be mediated by the activity of matrix metalloproteinase [132, 145].

A negative correlation has been demonstrated between Wnt activity and T cell signature [134, 146]. For example, Wnt inhibitors have been shown to significantly inhibit tumor progression and to increase the infiltration of $\mathrm{CD}^{+}$ $\mathrm{T}$ cells in the TME in the OC model [146].

The Wnt pathway has been shown to be involved in drug resistance in OC, and inhibition of the Wnt pathway can increase the sensitivity of OC cells to chemotherapeutic agents [147]. In recent years, the Wnt pathway has also been shown to contribute to ameliorating adverse reactions caused by chemotherapy in OC. For example, in a mouse model of OC, the Wnt agonist BIO showed a significant therapeutic effect on cisplatin-induced acute kidney injury without affecting cisplatin's antitumor activity. One of the mechanisms was the activation of Wnt and its downstream pathway, which inhibits the production of excessive ROS in cells and thus reduces apoptosis in renal tubular cells [148].

2.2.4. Notch Signaling Pathway. Notch and its intracellular domain (NICD) have been shown to be overexpressed in $\mathrm{OC}$, and this is closely related to poorer prognosis in patients with OC [149-152]. OC cells in which Notch is activated show resistance to carboplatin, and it has been reported that methylseleninic acid can synergistically enhance the killing effect of carboplatin on OVCA429/NICD3 OC cells (which have a constitutively active form of Notch3) and that this can be promoted by ROS [153]. A correlation between Notch and NO/soluble guanylate cyclase (SGC) signaling has also been found. Low concentrations of $\mathrm{NO}$ can promote the progression of cancer, while many physiological functions of NO are mediated by SGC [103], and it has been confirmed that activation of the Notch pathway can enhance NO/SGC signaling in OC cells thereby promoting the proliferation and survival of OC cells [103]. In addition, a crosstalk has been shown between the Wnt/ $\beta$-catenin and Notch pathways in OC. On the one hand, the $\beta$-catenin and Notch pathways synergistically promote proliferation and migration of OC cells, while on the other hand, inhibition of $\beta$-catenin increases the activity of the Notch system, thus showing the compensatory activities between the two pathways [154]. A method for detecting the activity of Notch has been developed that calculates the pathway activity score based upon the expression level of the conserved Notch target genes, and this has had a positive effect on clinical research and drug development for various diseases, including OC [155].

2.3. OS-Mediated Alterations of Transcription Factors in OC. In addition to signaling pathways, the development and progression of OC caused by OS is also closely related to several transcription factors. The following will focus on the regulation of $\mathrm{OC}$ by $\mathrm{P} 53, \mathrm{NF}-\kappa \mathrm{B}$, and $\mathrm{HIF}-1 \alpha$ under conditions of OS. 


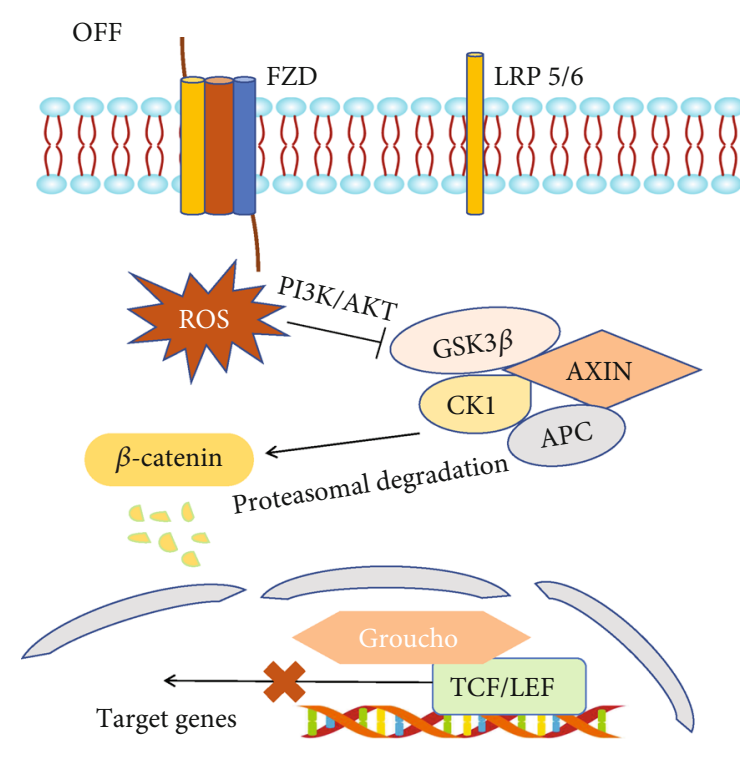

(a)

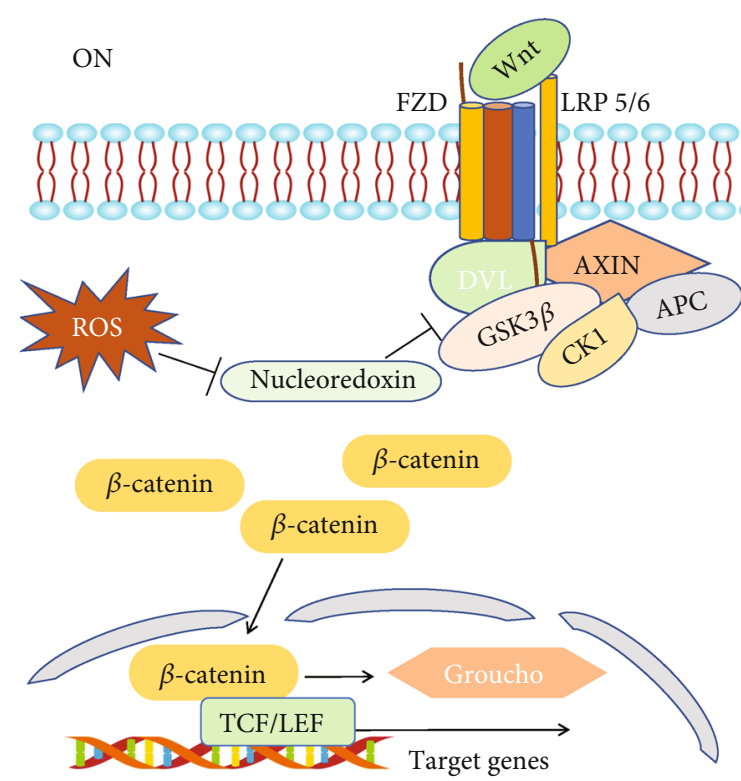

(b)

FIGURE 5: The transduction mechanism of the OS-mediated Wnt/ $\beta$-catenin signaling pathway in OC. (a) In the absence of the Wnt ligand, the level of intracellular $\beta$-catenin is controlled by a "destruction complex" formed by glycogen synthase kinase $3 \beta$ (GSK3 $\beta$ ), casein kinase 1 (CK1), adenomatous polyposis coli (APC), and AXIN (a cytoplasmic protein regulating G-protein signaling) [138]. The destruction complex ubiquitinates and degrades $\beta$-catenin, thus preventing it from entering the nucleus to bind to the TCF/LEF complex and activate its target genes $[132,137]$. ROS phosphorylate and inactivate GSK3 $\beta$ by activating the PI3K/AKT pathway and thus inhibiting GSK3 $\beta$ 's ability to degrade $\beta$-catenin $[138,139]$. (b) In the presence of the Wnt ligand, the ligand binds to the cell surface receptor encompassing frizzled (FZD) and low-density lipoprotein receptor-related protein 5/6 (LRP5/6), leading to their conformational changes [137]. Disheveled (DVL) is then recruited and phosphorylated by FZD. Phosphorylated DVL in turn recruits AXIN, which inactivates the destruction complex and promotes the accumulation of $\beta$-catenin in the cytosol [138]. Subsequently, $\beta$-catenin is translocated into the nucleus where it displaces Groucho and binds to TCF/LEF members. Together with coactivators, the transcription of downstream target genes is initiated [132]. ROS can upregulate the Wnt pathway by oxidizing and inactivating nucleoredoxin, which inhibits DVL [136].

As a well-known tumor suppressor gene, p53 plays a major role in regulating cell proliferation, apoptosis, DNA repair, and genomic stability $[156,157]$, and about $96 \%$ of HGSC cases carry p53 mutations [158]. In contrast to wild-type p53, mutant p53 has been shown to stimulate the production of ROS by regulating redox-related signaling pathways and enzymes [159-161]. In addition, mutant p53 has been shown to activate glycolysis in tumor cells in order to maintain the Warburg effect, thus promoting cancer progression and tumor growth [159]. OS plays a role in the changes in p53 activity. OS has been shown to upregulate p53 in OC cells, thus inducing apoptosis and autophagy $[162,163]$. In addition, high levels of OS can enhance the stability of mutant p53 [160, 164]. Interestingly, Padmanabhan et al. showed that apoptosis in OC cells was induced by OS and protein toxicity triggered by zinc oxide nanoparticles independently of the p53 mutation state [165].

$\mathrm{NF}-\kappa \mathrm{B}$ is another important transcription factor involved in inflammation, immunity, apoptosis, and drug resistance $[166,167]$. NF- $\kappa \mathrm{B}$ has been shown to contribute to the initiation of tumorigenesis and to play a crucial role in tumor cell proliferation and survival [168]. The p65 and p50 NF- $\kappa$ B subunits have been shown to be highly expressed in OC patients and to be associated with poor prognosis [169]. NF- $\kappa$ B can protect OC cells from OS by regulating the expression of antioxidant genes [170], and MnSOD
(SOD2) seems to be the main target of NF- $\kappa \mathrm{B}$ [171]. Additionally, NF- $\kappa \mathrm{B}$ regulates the production of $\mathrm{NO}$ through iNOS, thus inducing angiogenesis and increasing resistance to apoptosis [172]. However, it has been shown that NF- $\kappa$ B may also function as a potential tumor suppressor in some specific cases [168]. In contrast, ROS can promote the nuclear translocation of NF- $\kappa \mathrm{B}$ [173], and the inhibition of OS in OC cells has been shown to inactivate NF- $\kappa$ B, thus inhibiting tumor progression [174]. Interestingly, Cys62, a key cysteine residue in the P50 domain, needs to be reduced in order to obtain effective NF- $\kappa$ B DNA binding [173]. In addition, there is crosstalk between NF- $\kappa \mathrm{B}$ and Nrf2 under pathological conditions, and the two proteins inhibit each other [175].

Hypoxia-inducible factor 1 alpha (HIF- $1 \alpha$ ) is a key regulator of cellular response to hypoxia, which can be detected in many carcinomas, including OC. HIF- $1 \alpha$ is closely related to tumor growth and angiogenesis [176, 177]. Under normal oxygen levels, HIF- $1 \alpha$ is hydroxylated by prolyl hydroxylase (PHD), after which it binds to von Hippel-Lindau tumor suppressor protein and is subsequently ubiquitinated and degraded by proteasomes. However, under hypoxic conditions, the activity of PHD decreases, resulting in HIF- $1 \alpha$ escaping from proteasome degradation $[177,178]$. In addition to hydroxylation, SUMOylation and S-nitrosation are also related to the stability of HIF-1 $\alpha$ [179]. Under hypoxic 
conditions, the levels of ROS in OC cells are increased paradoxically and this activates HIF- $1 \alpha[178,180]$. HIF- $1 \alpha$ has been shown to inhibit E-cadherin by upregulating the expression of its target genes, such as SNAIL [180], LOX [181], and AEG-1 [182], thus leading to EMT and promoting the invasion and metastasis of OC. Meanwhile, the reduced expression of HIF- $1 \alpha$ suppresses the growth of OC cells $[183,184]$. HIF- $1 \alpha$ is also involved in the regulation of chemotherapy resistance, and it has been reported that HIF- $1 \alpha$ can promote chemotherapy resistance by blocking the cell cycle in the G0/G1 phase [185]. Additionally, the tumor pharmacokinetic DCE-MRI perfusion parameters in patients with OC are negatively correlated with the expression level of HIF-1 $\alpha$, which can be used to screen the tumor characteristics of OC and help clinicians choose the best treatment options [186].

2.4. OS-Mediated Alterations of the TME in OC. The TME refers to the niche in which tumor cells interact with the host stroma, including different immune cells, fibroblasts, endothelial cells, and metabolites [187]. OC has a unique TME, and coevolution of cancer cells with their surroundings is an indispensable prerequisite for OC progression [188]. OS is involved in regulating OC progression by affecting components such as tumor-associated macrophages (TAMs), neutrophils, myeloid-derived suppressor cells (MDSCs), Treg cells, ascites, and lysophosphatidic acid (LPA) in the TME.

TAMs are a major inflammatory component of the tumor microenvironment and are associated with tumor growth and metastasis [189]. In TAMs, $\mathrm{H}_{2} \mathrm{O}_{2}$ triggers the expression of tumor necrosis factor- $\alpha$ (TNF- $\alpha$ ) by activating the p38 and JNK pathways [190]. In turn, TNF induces ROS/RNS generation by controlling TNF signaling downstream of TNF receptors [191]. OS has been reported to drive TAMs to release different cytokines like TNF- $\alpha$, interleukin 1- $\alpha$ (IL1- $\alpha$ ), IL-6, IL-10, and transforming growth factor $\beta$ (TGF $\beta$ ) which results in the progression of OC [188, $192]$. A study showed that OC cells can induce the production of itaconic acid (a metabolite resulting from tumor cell interactions with TAMs) in resident peritoneal macrophages, which contributed to the increase in oxidative phosphorylation and ROS and resulted in tumor growth [193].

Neutrophils, as the first line of defense against infection, are implicated in cancer-related inflammation [187]. Compared with the neutrophils of healthy women, the neutrophils isolated from OC patients show enhanced functional activity and higher ROS levels, which contribute to tumor progression and metastasis [194]. A study on dormancy models of OC and lung cancer showed that in response to stress hormones, the proinflammatory protein S100A8/A9 is released by neutrophils, and this leads to the accumulation of oxidized lipids in polymorphonuclear neutrophils by inducing the activation of myeloperoxidase. Moreover, oxidized lipids directly activate the proliferation of dormant tumor cells by upregulating the fibroblast growth factor receptor pathway [195].

MDSCs can inhibit immune responses in cancer patients and can lead to immune evasion [188] through the production and release of ROS and RNS [196] and are an important source of immunosuppression in OC [197]. The number of MDSCs is significantly increased in OC patients, especially monocytic MDSCs [198], and MDSCs can enhance the stemness of EOC cells by inducing the CSF2/p-STAT3 signaling pathway [199]. MDSCs can induce an increase in ROS [200], while ROS inhibitors can reverse MDSCmediated T lymphocyte inhibition [201]. Another study showed that MDSCs generate NO through iNOS and that NO induces $\mathrm{T}$ cell apoptosis by inhibiting the Jak3/STAT5 signaling pathway [202]. In addition, tumor-infiltrating MDSCs have been shown to produce $\mathrm{ONOO}^{-}$, which nitrates tyrosine residues in the T cell receptor-CD8 complex, thus disrupting the binding of specific peptide-major histocompatibility complex dimers to $\mathrm{CD} 8^{+} \mathrm{T}$ cells [203].

Other cells in the TME are also involved in regulating tumor progression under conditions of OS. For example, Treg cells are implicated in tumor-associated immunosuppression and are vulnerable to OS, which has been shown to induce apoptosis in Treg cells. Interestingly, apoptotic Treg cells have been shown to enhance immunosuppression and to mediate the immune escape of tumor cells [204]. In addition, tumorderived microvesicles contribute to restoring and improving the antigen processing capacity of clinical grade dendritic cells, which is related to the increase in ROS $[205,206]$.

Ascites is a key factor in the TME of OC and serves as a carrier to promote the spread of tumor cells to other pelvic and peritoneal organs [188], and OS plays an important role in this process [207]. Pakula et al. reported that malignant ascites generated by serous ovarian tumors triggers OS in human peritoneal mesothelial cells (HPMCs) by inducing cytochrome C oxidase and NADH dehydrogenase, which results in the senescence of HPMCs and thus promotes the adhesion, proliferation, and migration of OC cells [73]. In addition, malignant ascites can also increase the antioxidant capacity of OC cells [208]. GPx3 has been shown to be necessary for the survival of high-grade serous adenocarcinomas in ascites because it mediates the clearance of extracellular OS [209].

LPA, the second major group of lipids found in ascites [188], has been reported to be significantly increased in the ascites of OC patients and to promote the survival and proliferation of OC cells [210]. LPA stimulates the production of NOX-mediated ROS in OC cells, which is essential for the signal transduction of AKT, ERK, and NF- $\kappa \mathrm{B}$, leading to the proliferation of OC cells $[210,211]$. Blocking the LPA-dependent survival signaling pathway in OC cells has been shown to increase the production of ROS and to promote Taxol-induced apoptosis [212].

Hypoxia is a typical feature of the TME of malignant tumors and is attributed to the uncontrolled and rapid proliferation and irregular vascularization of the tumor [213]. Under hypoxic conditions, VEGF in malignant tumor cells is upregulated, which increases the metastatic ability of cancer cells [208].

\section{Potential OS-Related Therapeutic Targets in OC}

Based on the role of OS in OC, resolving the imbalance between oxidants and antioxidants is of great clinical 
importance in treating OC, and agents that modulate OS are regarded as an important choice for the prevention and treatment of OC. In recent years, many agents, including chemotherapeutic drugs, natural extracts and Chinese medicines, and nanoparticles, have received broad attention from the public. These agents play different roles in dealing with aberrant OS in OC. Most of these agents, such as berberine and methotrexate, work by promoting OS to induce oxidative damage to DNA and subsequent apoptosis in OC cells. Some of these agents such as Ganoderma lucidum and bisdemethoxycurcumin can activate antioxidant enzymes and reduce superoxide generation to decrease $\mathrm{OS}$ and inhibit the adhesion, invasion, and migration of $\mathrm{OC}$ cells. Table 1 presents the three categories of therapeutic agents currently used for treating OC.

3.1. Chemotherapeutic Drugs. Chemotherapeutics can exhibit toxicity by inducing OS, inflammation, apoptosis, and abnormalities in neurotransmitter metabolism. ROS and RNS generated by anthracyclines and novel oxazolinoanthracyclines have drawn attention as novel signal mediators that are involved in the growth, differentiation, progression, and death of cancer cells [214]. Platinum coordination complexes, alkylating agents, camptothecins, and arsenic agents can induce high levels of ROS, while taxanes, vinca alkaloids, nucleotide analogues, and antimetabolites, including antifolates and nucleosides, generate lower levels of ROS [215]. Diosmetin has been shown to upregulate the levels of BAX while downregulating the expression of $\mathrm{Bcl} 2$, inhibiting $\mathrm{Nrf2}$, and inducing the production of ROS [216]. Methotrexate has been shown to induce apoptosis in SKOV-3 cells via the ROS-mediated BAX/Bcl-2-Cyt-c release cascade [217]. PARP inhibitors have been shown to upregulate NADPH oxidases 1 and 4 and to have an antitumor effect by elevating OS in OC cells [218]. Cisplatin has been shown to downregulate HIF- $1 \alpha$ in cisplatin-sensitive OC cells, and cisplatin plus-downregulated HIF- $1 \alpha$ has been shown to induce apoptosis in cisplatin-resistant OC cells by inducing the overproduction of ROS [219]. In addition, the methylseleninic acid mentioned earlier, a promising future chemotherapeutic agent, has been shown to contribute to inhibiting OC progression by enhancing $\mathrm{T}$ cell-mediated tumor cell killing.

3.2. Natural Compounds and Chinese Medicines. Many extracts of natural compounds and Chinese medicines have been used in treating OC. Juglone (5-hydroxy-1, 4-napthoquinone) is isolated from various plants [220] and can increase ROS, resulting in ROS-dependent apoptosis by inducing cytochrome $\mathrm{C}$ and caspase-3, which are proapoptotic proteins involved in OS [221]. Moreover, juglone can upregulate $B A X$ (a gene that promotes apoptosis) and downregulate $B C L 2$ (an apoptosis suppressor gene). Ailanthone, a natural compound extracted from the tree Ailanthus altissima, has been shown to decrease the proliferation and migration of cancer cells through a mechanism involving the posttranslational reduction of Nrf2 proteins, which in turn entails an increase in OS [222]. Olive leaf extract reduces OVCAR-3 cell viability by inducing cell cycle arrest, and it also induces apoptosis and increases the level of intracellular and mitochondrial ROS and decreases the activity of ROS scavenging enzymes [223]. Procyanidin, an extract from natural cocoa powder, increases ROS and activates caspase-3, thus leading to apoptosis [224]. Resveratrol (3,5, $4^{\prime}$-trihydroxystilbene), from the roots of white hellebore and Polygonum cuspidatum, effectively induces OC stem cell death in a concentration-dependent manner, the mechanism of which might be through caspase-dependent apoptosis [225], the activation of caspase- 9 and caspase- 3 expression, and the downregulation of Notch expression [226]. The resveratrol derivative $3,3^{\prime}, 4,4^{\prime}$-tetrahydroxy-trans-stilbene also induces apoptosis and reduces proliferation via ROSinduced DNA damage [227]. Gedunin inhibits proliferation by upregulating cytochrome $\mathrm{C}$ and caspase-9/3, thus causing ROS-dependent apoptosis [228]. Ganoderma lucidum was demonstrated to induce the antioxidants SOD, CAT, NADPH, and GSTP1 via the Nrf2-mediated signaling pathway to provide chemoprotection against carcinogenicity [229]. Antrodia salmonea acts as a potent inducer of apoptosis in OC by upregulating the proapoptotic proteins caspase-9/3 and BAX, downregulating the antiapoptotic protein Bcl-2, and inactivating $\mathrm{PI} 3 \mathrm{~K} / \mathrm{AKT}$, all of which are mediated by ROS generation [129].

3.3. Nanoparticles. As emerging novel anticancer therapeutics, nanoparticles with good histocompatibility and targeting ability are becoming a hot research topic in the diagnosis and treatment of OC because of their small diameter and uniform distribution [230]. $\mathrm{ZnO}$ nanoparticles can induce severe oxidative and proteotoxic stress in OC cells through a dramatic decrease in intracellular glutathione levels [165], and $\mathrm{ZnO}$ nanoparticles with an average size of $20 \mathrm{~nm}$ were able to induce significant cytotoxicity in HOC cells by inducing increased levels of intracellular ROS [162]. SeChry and folate-targeted polyurea dendrimer generation four (SeChry@PURE ${ }_{\mathrm{G} 4}$-FA) nanoparticles can increase OS leading to GSH depletion and can inhibit the $\mathrm{H}_{2} \mathrm{~S}$-synthesizing enzyme cystathionine $\beta$-synthase, while upregulating the expression of the cystine/glutamate antiporter system Xc [231]. Celastrol is derived from the Chinese herb Tripterygium wilfordii, and nanoparticles loaded with celastrol have been designed to specifically target OC cells thus leading to increased intracellular ROS levels and apoptosis of tumor cells and thus achieving a therapeutic effect against OC [232]. These studies suggest that nanomaterials, especially nanomaterials combined with therapeutic agents, will play a crucial role in treating OC, and future research should focus on exploring the mechanisms through which these particles exert their effects on OC.

\section{Concluding Remarks and Future Prospects}

Accumulating evidence has shown the critical role of OS in the pathogenesis of OC via genetic changes and alterations to signaling pathways, transcription factors, and the TME. OS-mediated genetic alterations, such as oxidative damage to nuclear DNA and mtDNA, DNA hypomethylation, and abnormal expression of microRNA, can trigger 


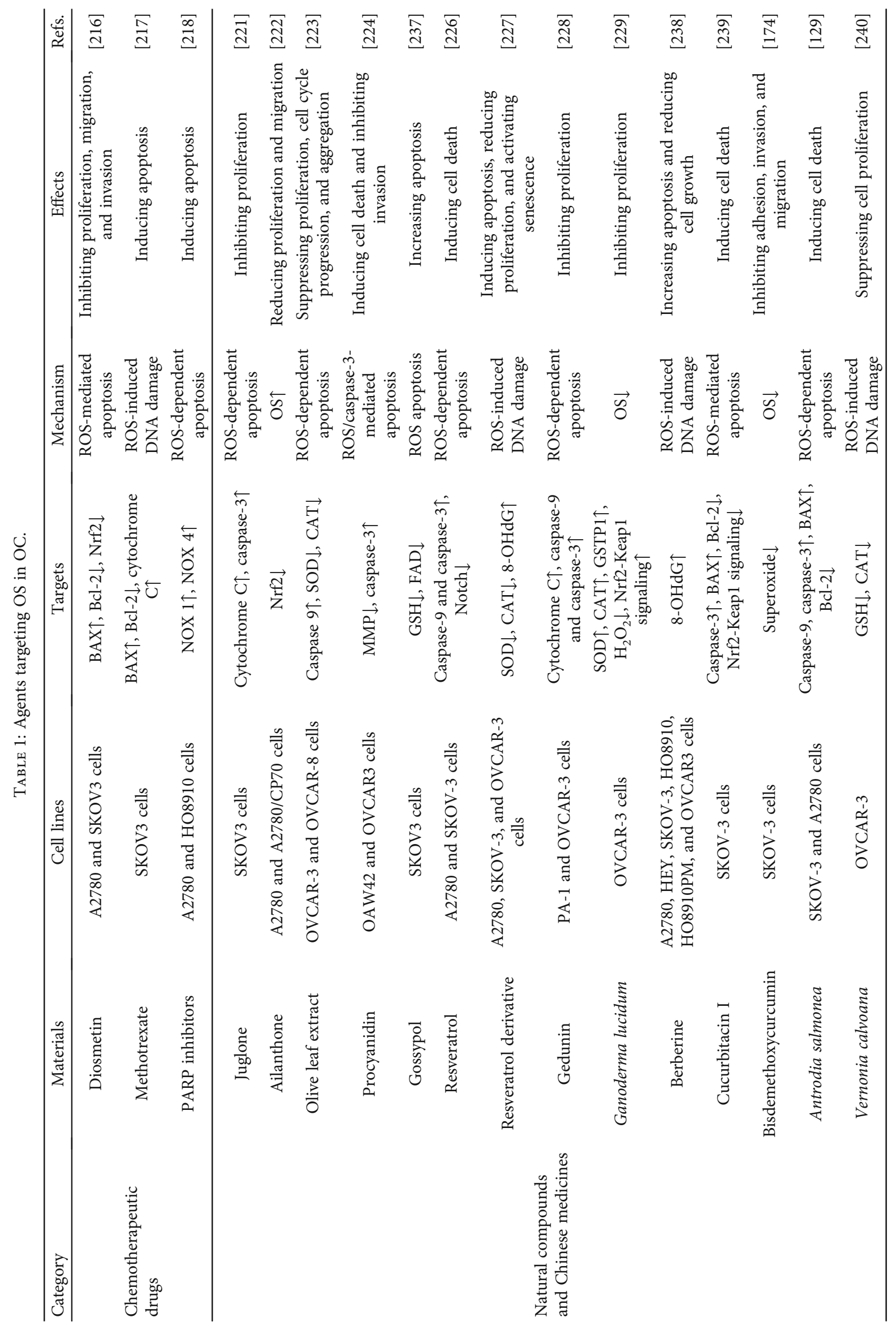




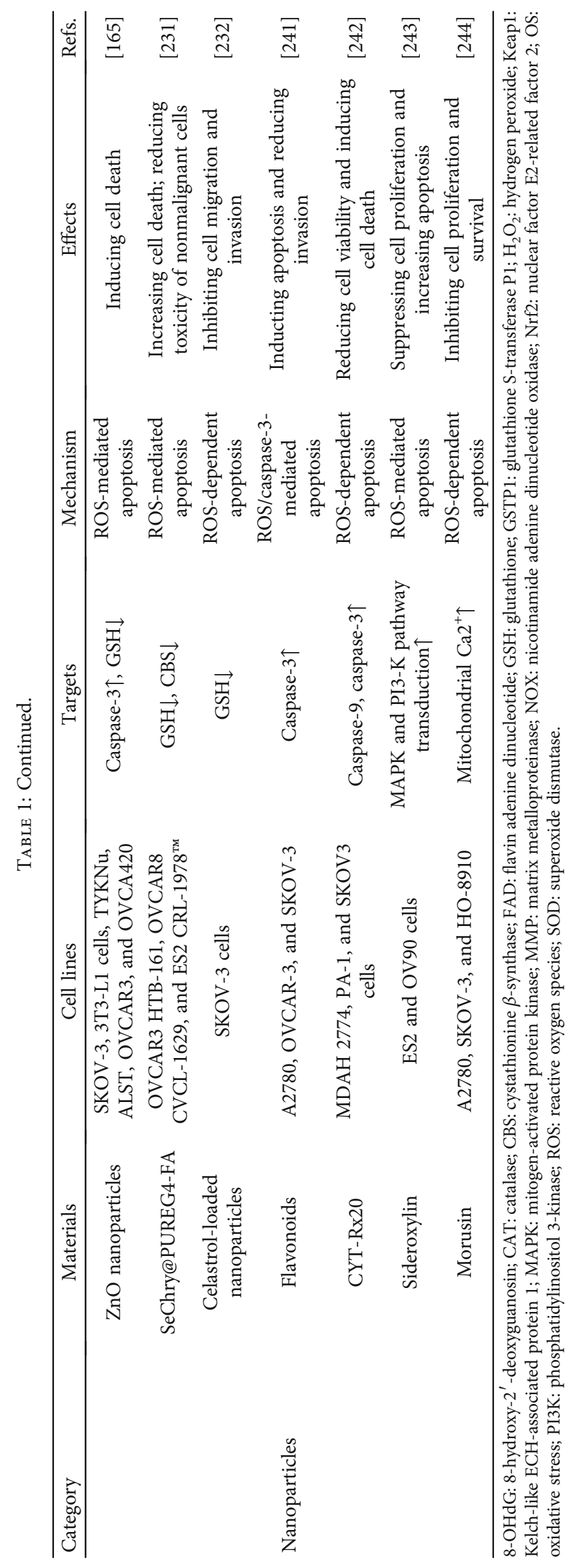


OC. OS-mediated signaling pathways, such as Keap1-Nrf2ARE, PI3K/AKT/mTOR, Wnt/ $\beta$-catenin, and Notch, play important roles in regulating the progression of OC. Among these, activation of the Nrf2 pathway is considered to be a double-edged sword in OC because it maintains the stability of the normal ovarian cell environment and genome in order to prevent OS-induced carcinogenesis, while at the same time, it protects tumor cells from OS thereby enhancing the invasion and chemoresistance of OC. The PI3K/AKT/mTOR and $\mathrm{Wnt} / \beta$-catenin pathways contribute to the proliferation, migration, and chemoresistance of OC, and they can be activated by OS. The OS-mediated Notch pathway is closely related to poor prognosis in patients with OC; however, the specific mechanism of action remains to be further studied. The transcription factors $\mathrm{p} 53, \mathrm{NF}-\kappa \mathrm{B}$, and HIF- $1 \alpha$ are also ROS sensitive, and redox modification of these molecules can be instrumental in the initiation and progression of OC. Finally, OS is involved in regulating OC progression by affecting components such as TAMs, neutrophils, MDSCs, Treg cells, ascites, and LPA in the TME of OC.

We have also outlined three treatment strategies to target aberrant OS in OC, including chemotherapeutic drugs, natural compound extracts or Chinese medicine, and nanoparticles. Their mechanisms of action may be through affecting oxidative damage to DNA, by regulating signaling pathways such as Notch and Keap1-Nrf2-ARE and transcription factors such as HIF- $1 \alpha$ and by affecting components of the TME. These agents play different roles in dealing with aberrant OS in OC. Most of them can promote OS to induce DNA oxidative damage and ROS-dependent apoptosis of OC cells, while some agents can activate antioxidant enzymes and reduce superoxide generation to decrease OS. All of them contribute to inhibiting the adhesion, invasion, and migration of OC cells. There is a multitarget effect between OC and OS, and future experiments in clinic are needed to validate the relationship between OS and OC.

Abbreviations

GST:
$\mathrm{H}_{2} \mathrm{O}_{2}:$
HIF-1 $\alpha$ :
HGSC:
HPMCs:
HRR:
IL:
iNOS:
Keap1:
LPA:
Maf:
MAPK:
MDSCs:
MIEF2:
miRNA:
mtDNA:
mTOR:
mTORC1:
NADPH:
NICD:
NO:
NOX:
Nrf2:
OC:
${ }^{1} \mathrm{O}_{2}:$
O ${ }^{-}:$
OH:
ONOO-:
OS:
PGC1 $\alpha:$

PHD:

PI3K:

PIP3:

PIP2:

PPP:

PRX:

PTEN:

PTP:

ROS:

RNS:

RTK:

SeChry@PUREG4-FA: SeChry and folate-targeted polyurea

SGC:

SOD:

SOD2:

TAMs:

Tf:

TGF $\beta$ :

TME:

TNF:

TRX:

VEGF:

VHL:

$\mathrm{XO}$ :
Glutathione S-transferases

Hydrogen peroxide

Hypoxia-inducible factor 1 alpha

High-grade serous carcinoma

Human peritoneal mesothelial cells

Homologous recombination repair Interleukin

Inducible nitric oxide synthase

Kelch-like ECH-associated protein 1

Lysophosphatidic acid

Musculoaponeurotic fibrosarcoma

Mitogen-activated protein kinase

Myeloid-derived suppressor cells

Mitochondrial elongation factor 2

MicroRNA

Mitochondrial DNA

Mammalian target of rapamycin

MTOR complex 1

Nicotinamide adenine dinucleotide The intracellular domain of Notch Nitric oxide

Nicotinamide adenine dinucleotide oxidase

Nuclear factor E2-related factor 2

Ovarian cancer

Singlet oxygen

Superoxide anion

Hydroxyl radical

Peroxynitrite anion

Oxidative stress

Peroxisome proliferator-activated receptor- $\gamma$ coactivator $1 \alpha$

Prolyl hydroxylase

Phosphatidylinositol 3-kinase

Phosphatidylinositol trisphosphate Phosphorylates phos-

phatidylinositol bisphosphate

Pentose phosphate pathway

Peroxiredoxin

Phosphatase and tensin homolog

Protein tyrosine phosphatase

Reactive oxygen

Reactive nitrogen species

Receptor tyrosine kinase

dendrimer generation four

Soluble guanylate cyclase

Superoxide dismutase

MnSOD

Tumor-associated macrophages

Transferrin

Transforming growth factor $\beta$

Tumor microenvironment

Tumor necrosis factor

Thioredoxin

Vascular endothelial growth factor von Hippel-Lindau tumor suppressor protein

Xanthine oxidase. 


\section{Conflicts of Interest}

The authors declare no conflict of interest.

\section{Authors' Contributions}

Dan-Ni Ding conceptualized the study. Dan-Ni Ding prepared the original draft. Fang-Yuan Liu, Liang-Zhen Xie, and Feng-Juan Han reviewed and edited the manuscript. Ying Shen and Jia Li were involved in finding references. Ying Guo and Yang Fu prepared the figures. Fang-Yuan Liu and Feng-Juan Han supervised the study. Feng-Juan Han was responsible for the funding acquisition. FangYuan Liu and Feng-Juan Han are cocorresponding authors. All authors have read and agreed to the published version of the manuscript.

\section{Acknowledgments}

This study was funded by the National Natural Science Foundation of China (82074484).

\section{References}

[1] F. Bray, J. Ferlay, I. Soerjomataram, R. L. Siegel, L. A. Torre, and A. Jemal, "Global Cancer Statistics 2018: GLOBOCAN estimates of incidence and mortality worldwide for 36 cancers in 185 countries," CA: A Cancer Journal for Clinicians, vol. 68, no. 6, pp. 394-424, 2018.

[2] P. M. Webb and S. J. Jordan, "Epidemiology of epithelial ovarian cancer," Best Practice \& Research. Clinical Obstetrics \& Gynaecology, vol. 41, pp. 3-14, 2017.

[3] R. J. Kurman and I.-M. Shih, "The Dualistic Model of Ovarian Carcinogenesis: Revisited, Revised, and Expanded," The American Journal of Pathology, vol. 186, no. 4, pp. 733-747, 2016.

[4] J. Ducie, F. Dao, M. Considine et al., "Molecular analysis of high-grade serous ovarian carcinoma with and without associated serous tubal intra-epithelial carcinoma," Nature Communications, vol. 8, no. 1, p. 990, 2017.

[5] D. D. Bowtell, S. Böhm, A. A. Ahmed et al., "Rethinking ovarian cancer Ii: reducing mortality from high-grade serous ovarian cancer," Nature Reviews Cancer, vol. 15, no. 11, pp. 668-679, 2015.

[6] T. R. Soong, D. M. Dinulescu, W. Xian, and C. P. Crum, "Frontiers in the Pathology and Pathogenesis of Ovarian Cancer: Cancer Precursors and "Precursor Escape"," Hematology/Oncology Clinics of North America, vol. 32, no. 6, pp. 915-928, 2018.

[7] S. Lheureux, C. Gourley, I. Vergote, and A. M. Oza, "Epithelial ovarian cancer," The Lancet, vol. 393, no. 10177, pp. 1240-1253, 2019.

[8] U. A. Matulonis, A. K. Sood, L. Fallowfield, B. E. Howitt, J. Sehouli, and B. Y. Karlan, "Ovarian cancer," Nature Reviews. Disease Primers, vol. 2, no. 1, 2016.

[9] J. Ham, W. Lim, K. Kim et al., "Gentisyl alcohol inhibits proliferation and induces apoptosis via mitochondrial dysfunction and regulation of Mapk and Pi3k/Akt pathways in epithelial ovarian cancer cells," Marine Drugs, vol. 17, no. 6, p. 331, 2019.
[10] Z. Duračková, "Some Current Insights into Oxidative Stress," Physiological Research, vol. 59, no. 4, pp. 459-469, 2010.

[11] S. Reuter, S. C. Gupta, M. M. Chaturvedi, and B. B. Aggarwal, "Oxidative stress, inflammation, and cancer: how are they linked?," Free Radical Biology \& Medicine, vol. 49, no. 11, pp. 1603-1616, 2010.

[12] A. M. Pisoschi and A. Pop, "The role of antioxidants in the chemistry of oxidative stress: a review," European Journal of Medicinal Chemistry, vol. 97, pp. 55-74, 2015.

[13] J. Navarro-Yepes, L. Zavala-Flores, A. Anandhan et al., "Antioxidant Gene Therapy against Neuronal Cell Death," Pharmacology \& Therapeutics, vol. 142, no. 2, pp. 206-230, 2014.

[14] A. Sharaf, de Michele, A. Sharma, S. Fakhari, and Oborník, "Transcriptomic analysis reveals the roles of detoxification systems in response to mercury in Chromera Velia," Biomolecules, vol. 9, no. 11, p. 647, 2019.

[15] W. Dröge, "Free radicals in the physiological control of cell function," Physiological Reviews, vol. 82, no. 1, pp. 47-95, 2002.

[16] G. M. Saed, M. P. Diamond, and N. M. Fletcher, "Updates of the role of oxidative stress in the pathogenesis of ovarian cancer," Gynecologic Oncology, vol. 145, no. 3, pp. 595-602, 2017.

[17] K. Shankar and H. M. Mehendale, "Oxidative stress," in Encyclopedia of Toxicology, pp. 735-737, Elsevier Inc., 2014.

[18] D. Basak, M. N. Uddin, and J. Hancock, "The role of oxidative stress and its counteractive utility in colorectal cancer (Crc)," Cancers, vol. 12, no. 11, p. 3336, 2020.

[19] A. O. Oyewole and M. A. Birch-Machin, "Mitochondria-targeted antioxidants," The FASEB Journal, vol. 29, no. 12, pp. 4766-4771, 2015.

[20] A. Vilchez, F. Acevedo, M. Cea, M. Seeger, and R. Navia, "Applications of electrospun nanofibers with antioxidant properties: a review," Nanomaterials, vol. 10, no. 1, p. 175, 2020.

[21] T. Ismail, Y. Kim, H. Lee, D. S. Lee, and H. S. Lee, "Interplay between mitochondrial peroxiredoxins and Ros in cancer development and progression," International Journal of Molecular Sciences, vol. 20, no. 18, p. 4407, 2019.

[22] T. Finkel, "Signal transduction by reactive oxygen species," Journal of Cell Biology, vol. 194, no. 1, pp. 7-15, 2011.

[23] A. S. Veskoukis, A. M. Tsatsakis, and D. Kouretas, "Dietary oxidative stress and antioxidant defense with an emphasis on plant extract administration," Cell Stress \& Chaperones, vol. 17, no. 1, pp. 11-21, 2012.

[24] M. Benhar, "Roles of mammalian glutathione peroxidase and thioredoxin reductase enzymes in the cellular response to nitrosative stress," Free Radical Biology \& Medicine, vol. 127, pp. 160-164, 2018.

[25] A. Kirtonia, G. Sethi, and M. Garg, "The multifaceted role of reactive oxygen species in tumorigenesis," Cellular and Molecular Life Sciences, vol. 77, no. 22, pp. 4459-4483, 2020.

[26] S. Di Meo and P. Venditti, "Evolution of the knowledge of free radicals and other oxidants," Oxidative Medicine and Cellular Longevity, vol. 2020, Article ID 9829176, 32 pages, 2020.

[27] B. M. Bakadia, B. O. O. Boni, A. A. Q. Ahmed, and G. Yang, "The impact of oxidative stress damage induced by the environmental stressors on Covid-19," Life Sciences, vol. 264, article 118653, 2021.

[28] G. Pizzino, N. Irrera, M. Cucinotta et al., "Oxidative stress: harms and benefits for human health," Oxidative Medicine 
and Cellular Longevity, vol. 2017, Article ID 8416763, 13 pages, 2017.

[29] V. Gautam, S. K. Kohli, S. Arora et al., "Antioxidant and antimutagenic activities of different fractions from the leaves of Rhododendron arboreum Sm. and their Gc-Ms profiling," Molecules, vol. 23, no. 9, p. 2239, 2018.

[30] Q. Wang, W. Guo, B. Hao et al., "Mechanistic study of TRPM2- $\mathrm{Ca}^{2+}$-CAMK2-BECN1 signaling in oxidative stressinduced autophagy inhibition," Autophagy, vol. 12, no. 8, pp. 1340-1354, 2016.

[31] J. D. Hayes, A. T. Dinkova-Kostova, and K. D. Tew, "Oxidative stress in cancer," Cancer Cell, vol. 38, no. 2, pp. 167-197, 2020.

[32] J. Lee, S. Giordano, and J. Zhang, "Autophagy, mitochondria and oxidative stress: cross-talk and redox signalling," Biochemical Journal, vol. 441, no. 2, pp. 523-540, 2012.

[33] V. Sosa, T. Moliné, R. Somoza, R. Paciucci, H. Kondoh, and M. E. Lleonart, "Oxidative stress and cancer: an overview," Ageing Research Reviews, vol. 12, no. 1, pp. 376-390, 2013.

[34] S. Kumari, A. K. Badana, M. M. G, S. G, and R. R. Malla, "Reactive oxygen species: a key constituent in cancer survival,” Biomarker Insights, vol. 13, 2018.

[35] C. A. Caneba, L. Yang, J. Baddour et al., "Nitric oxide is a positive regulator of the Warburg effect in ovarian cancer cells," Cell Death \& Disease, vol. 5, no. 6, article e1302, 2014.

[36] S. Galadari, A. Rahman, S. Pallichankandy, and F. Thayyullathil, "Reactive oxygen species and cancer paradox: to promote or to suppress?," Free Radical Biology \& Medicine, vol. 104, pp. 144-164, 2017.

[37] M. Dodson, R. Castro-Portuguez, and D. D. Zhang, "Nrf2 plays a critical role in mitigating lipid peroxidation and ferroptosis," Redox Biology, vol. 23, article 101107, 2019.

[38] M. Redza-Dutordoir and D. A. Averill-Bates, "Activation of apoptosis signalling pathways by reactive oxygen species," Biochimica et Biophysica Acta (BBA) - Molecular Cell Research, vol. 1863, no. 12, pp. 2977-2992, 2016.

[39] Z. Jiang, N. M. Fletcher, R. Ali-Fehmi et al., "Modulation of redox signaling promotes apoptosis in epithelial ovarian cancer cells," Gynecologic Oncology, vol. 122, no. 2, pp. 418-423, 2011.

[40] K. A. Graham, M. Kulawiec, K. M. Owens et al., "NADPH oxidase 4 is an oncoprotein localized to mitochondria," Cancer Biology \& Therapy, vol. 10, no. 3, pp. 223-231, 2010.

[41] R. S. Nomelini, L. C. . A. Ribeiro, B. M. Tavares-Murta, S. J. Adad, and E. F. Murta, "Production of nitric oxide and expression of inducible nitric oxide synthase in ovarian cystic tumors," Mediators of Inflammation, vol. 2008, Article ID 186584, 7 pages, 2008.

[42] Y. Hu, D. G. Rosen, Y. Zhou et al., "Mitochondrial Manganese-Superoxide Dismutase Expression in Ovarian Cancer:," Journal of Biological Chemistry, vol. 280, no. 47, pp. 39485-39492, 2005.

[43] L. P. Hemachandra, D. H. Shin, U. Dier et al., "Mitochondrial superoxide dismutase has a protumorigenic role in ovarian clear cell carcinoma," Cancer Research, vol. 75, no. 22, pp. 4973-4984, 2015.

[44] A. Chatterjee and S. Gupta, "The multifaceted role of glutathione S-transferases in cancer," Cancer Letters, vol. 433, pp. 33-42, 2018.

[45] M. V. Liberti and J. W. Locasale, "The Warburg effect: how does it benefit cancer cells?," Trends in Biochemical Sciences, vol. 41, no. 3, pp. 211-218, 2016.
[46] K. I. Pritchard, J. A. Julian, C. M. Holloway et al., "Prospective study of 2-[18F]Fluorodeoxyglucose positron emission tomography in the assessment of regional nodal spread of disease in patients with breast cancer: an Ontario Clinical Oncology Group study," Journal of Clinical Oncology, vol. 30, no. 12, pp. 1274-1279, 2012.

[47] T. Amano, A. Murakami, T. Murakami, and T. Chano, "Antioxidants and therapeutic targets in ovarian clear cell carcinoma," Antioxidants, vol. 10, no. 2, p. 187, 2021.

[48] F. Weinberg and N. S. Chandel, "Mitochondrial metabolism and cancer," Annals of the New York Academy of Sciences, vol. 1177, no. 1, pp. 66-73, 2009.

[49] A. Kuehne, H. Emmert, J. Soehle et al., "Acute activation of oxidative pentose phosphate pathway as first-line response to oxidative stress in human skin cells," Molecular Cell, vol. 59, no. 3, pp. 359-371, 2015.

[50] W. Ying, "NAD+/NADH and NADP+/NADPH in cellular functions and cell death: regulation and biological consequences," Antioxidants \& Redox Signaling, vol. 10, no. 2, pp. 179-206, 2008.

[51] V. Purohit, D. M. Simeone, and C. A. Lyssiotis, "Metabolic regulation of redox balance in cancer," Cancers, vol. 11, no. 7, p. 955, 2019.

[52] Y. Ding, C. Gong, D. Huang et al., "Synthetic lethality between Her2 and transaldolase in intrinsically resistant Her2-positive breast cancers," Nature Communications, vol. 9, no. 1, p. 4274, 2018.

[53] T. de Raedt, Z. Walton, J. L. Yecies et al., "Exploiting cancer cell vulnerabilities to develop a combination therapy for Ras-driven tumors," Cancer Cell, vol. 20, no. 3, pp. 400-413, 2011.

[54] A. C. Blackburn, K. I. Matthaei, C. Lim et al., "Deficiency of glutathione transferase zeta causes oxidative stress and activation of antioxidant response pathways," Molecular Pharmacology, vol. 69, no. 2, pp. 650-657, 2006.

[55] L. Zheng, S. Cardaci, L. Jerby et al., "Fumarate induces redoxdependent senescence by modifying glutathione metabolism," Nature Communications, vol. 6, no. 1, p. 6001, 2015.

[56] Y. Chen, S. Singh, A. Matsumoto et al., "Chronic glutathione depletion confers protection against alcohol-induced steatosis: implication for redox activation of Amp-activated protein kinase pathway," Scientific Reports, vol. 6, no. 1, article 29743, 2016.

[57] H. S. Marinho, C. Real, L. Cyrne, H. Soares, and F. Antunes, "Hydrogen peroxide sensing, signaling and regulation of transcription factors," Redox Biology, vol. 2, pp. 535-562, 2014.

[58] S. Faes and O. Dormond, "Pi3k and Akt: unfaithful partners in cancer," International Journal of Molecular Sciences, vol. 16, no. 9, pp. 21138-21152, 2015.

[59] P. D. Ray, B. W. Huang, and Y. Tsuji, "Reactive oxygen species (ROS) homeostasis and redox regulation in cellular signaling," Cellular Signalling, vol. 24, no. 5, pp. 981-990, 2012.

[60] M. Kleih, K. Bopple, M. Dong et al., "Direct impact of cisplatin on mitochondria induces ROS production that dictates cell fate of ovarian cancer cells," Cell Death \& Disease, vol. 10, no. 11, p. 851, 2019.

[61] L. Mosca, A. Ilari, F. Fazi, Y. G. Assaraf, and G. Colotti, "Taxanes in cancer treatment: activity, chemoresistance and its overcoming," Drug Resistance Updates, vol. 54, article 100742, 2021. 
[62] Y. Yamada, H. Shigetomi, A. Onogi et al., "Redox-active ironinduced oxidative stress in the pathogenesis of clear cell carcinoma of the ovary," International Journal of Gynecological Cancer, vol. 21, no. 7, pp. 1200-1207, 2011.

[63] T. Iwabuchi, C. Yoshimoto, H. Shigetomi, and H. Kobayashi, "Oxidative stress and antioxidant defense in endometriosis and its malignant transformation," Oxidative Medicine and Cellular Longevity, vol. 2015, Article ID 848595, 7 pages, 2015.

[64] H. Kobayashi, K. Ogawa, N. Kawahara et al., "Sequential molecular changes and dynamic oxidative stress in highgrade serous ovarian carcinogenesis," Free Radical Research, vol. 51, no. 9-10, pp. 755-764, 2017.

[65] Marí-Alexandre, Pellín Carcelén, C. Agababyan et al., "Interplay between microRNAs and oxidative stress in ovarian conditions with a focus on ovarian cancer and endometriosis," International Journal of Molecular Sciences, vol. 20, no. 21, p. 5322, 2019.

[66] G. M. Calaf, U. Urzua, L. Termini, and F. Aguayo, "Oxidative stress in female cancers," Oncotarget, vol. 9, no. 34, pp. 23824-23842, 2018.

[67] J. E. Klaunig and L. M. Kamendulis, "Therole Ofoxidativestress Incarcinogenesis," Annual Review of Pharmacology and Toxicology, vol. 44, no. 1, pp. 239-267, 2004.

[68] Y. Yang, S. Karakhanova, J. Werner, and A. V. Bazhin, "Reactive oxygen species in cancer biology and anticancer therapy," Current Medicinal Chemistry, vol. 20, no. 30, pp. 3677-3692, 2013.

[69] S. Shigeta, M. Toyoshima, K. Kitatani, M. Ishibashi, T. Usui, and N. Yaegashi, "Transferrin facilitates the formation of DNA double-strand breaks via transferrin receptor 1: the possible involvement of transferrin in carcinogenesis of high-grade serous ovarian cancer," Oncogene, vol. 35, no. 27, pp. 3577-3586, 2016.

[70] W. Ye, Y. Zhang, W. Hu, L. Wang, Y. Zhang, and P. Wang, "A sensitive FRET biosensor based on carbon dots-modified nanoporous membrane for 8-hydroxy-2'-Deoxyguanosine (8-OHdG) detection with Au@Zif-8 nanoparticles as signal quenchers," Nanomaterials, vol. 10, no. 10, p. 2044, 2020.

[71] A. Valavanidis, T. Vlachogianni, and C. Fiotakis, "8-hydroxy$2^{\prime}$-deoxyguanosine (8-OHdG): a critical biomarker of oxidative stress and carcinogenesis," Journal of Environmental Science and Health, Part C, vol. 27, no. 2, pp. 120-139, 2009.

[72] E. S. Hwang and P. E. Bowen, "DNA damage, a biomarker of carcinogenesis: its measurement and modulation by diet and environment," Critical Reviews in Food Science and Nutrition, vol. 47, no. 1, pp. 27-50, 2007.

[73] M. Pakuła, J. Mikuła-Pietrasik, Ł. Stryczyński et al., "Mitochondria-related oxidative stress contributes to ovarian cancer-promoting activity of mesothelial cells subjected to malignant ascites," The International Journal of Biochemistry \& Cell Biology, vol. 98, pp. 82-88, 2018.

[74] B. van Loon, E. Markkanen, and U. Hubscher, "Oxygen as a friend and enemy: how to combat the mutational potential of 8-oxo-guanine," DNA Repair, vol. 9, no. 6, pp. 604-616, 2010.

[75] L. Xu, T. Wu, S. Lu et al., "Mitochondrial superoxide contributes to oxidative stress exacerbated by DNA damage response in RAD51-depleted ovarian cancer cells," Redox Biology, vol. 36, article 101604, 2020.

[76] A. Ghosh, S. Bhattacharjee, S. P. Chowdhuri et al., "SCAN1TDP1 trapping on mitochondrial DNA promotes mitochon- drial dysfunction and mitophagy," Science Advances, vol. 5, no. 11, article eaax9778, 2019.

[77] S. Abedi, G. Yung, S. R. Atilano et al., "Differential effects of cisplatin on cybrid cells with varying mitochondrial DNA haplogroups," PeerJ, vol. 8, article e9908, 2020.

[78] M. W. van Gisbergen, A. M. Voets, M. H. Starmans et al., "How do changes in the mtDNA and mitochondrial dysfunction influence cancer and cancer therapy? Challenges, opportunities and models," Mutation Research, Reviews in Mutation Research, vol. 764, pp. 16-30, 2015.

[79] V. W. Liu, H. H. Shi, A. N. Cheung et al., "High incidence of somatic mitochondrial DNA mutations in human ovarian carcinomas," Cancer Research, vol. 61, no. 16, pp. 5998-6001, 2001.

[80] D. C. Wallace, "Mitochondria and cancer," Nature Reviews Cancer, vol. 12, no. 10, pp. 685-698, 2012.

[81] P. O. Van Trappen, T. Cullup, R. Troke et al., "Somatic mitochondrial DNA mutations in primary and metastatic ovarian cancer," Gynecologic Oncology, vol. 104, no. 1, pp. 129-133, 2007.

[82] J. W. Shay and H. Werbin, "Are mitochondrial DNA mutations involved in the carcinogenic process?," Mutation Research/Reviews in Genetic Toxicology, vol. 186, no. 2, pp. 149-160, 1987.

[83] M. Saki and A. Prakash, "DNA damage related crosstalk between the nucleus and mitochondria," Free Radical Biology \& Medicine, vol. 107, pp. 216-227, 2017.

[84] E. F. Fang, M. Scheibye-Knudsen, K. F. Chua, M. P. Mattson, D. L. Croteau, and V. A. Bohr, "Nuclear DNA damage signalling to mitochondria in ageing," Nature Reviews Molecular Cell Biology, vol. 17, no. 5, pp. 308-321, 2016.

[85] Y. Yang, S. Karakhanova, W. Hartwig et al., "Mitochondria and mitochondrial ROS in cancer: novel targets for anticancer therapy," Journal of Cellular Physiology, vol. 231, no. 12, pp. 2570-2581, 2016.

[86] J. Ni, Y. Wang, X. Cheng et al., "Pathogenic heteroplasmic somatic mitochondrial DNA mutation confers platinumresistance and recurrence of high-grade serous ovarian Cancer," Cancer Management and Research, vol. 12, pp. 11085-11093, 2020.

[87] F. Guerra, A. M. Perrone, I. Kurelac et al., "Mitochondrial DNA mutation in serous ovarian cancer: implications for mitochondria-coded genes in chemoresistance," Journal of Clinical Oncology, vol. 30, no. 36, pp. e373-e378, 2012.

[88] M. Ehrlich, "DNA hypomethylation in cancer cells," Epigenomics, vol. 1, no. 2, pp. 239-259, 2009.

[89] C. Luo, P. Hajkova, and J. R. Ecker, "Dynamic DNA methylation: in the right place at the right time," Science, vol. 361, no. 6409, pp. 1336-1340, 2018.

[90] Q. Wu and X. Ni, "ROS-mediated DNA methylation pattern alterations in carcinogenesis," Current Drug Targets, vol. 16, no. 1, pp. 13-19, 2015.

[91] D. V. Maltseva, A. A. Baykov, A. Jeltsch, and E. S. Gromova, "Impact of 7,8-dihydro-8-oxoguanine on methylation of the CpG site by Dnmt3a," Biochemistry, vol. 48, no. 6, pp. 1361-1368, 2009.

[92] C. A. Koczor, I. Ludlow, E. Fields et al., "Mitochondrial polymerase gamma dysfunction and aging cause cardiac nuclear DNA methylation changes," Physiological Genomics, vol. 48, no. 4, pp. 274-280, 2016.

[93] H. Hiura, H. Okae, H. Kobayash et al., "High-throughput detection of aberrant imprint methylation in the ovarian 
cancer by the bisulphite PCR-Luminex method," BMC Medical Genomics, vol. 5, no. 1, p. 8, 2012.

[94] L. Qin, T. Li, and Y. Liu, "High Slc4a11 expression is an independent predictor for poor overall survival in grade $3 / 4$ serous ovarian cancer," PLoS One, vol. 12, no. 11, article e0187385, 2017.

[95] L. Batista, T. Gruosso, and F. Mechta-Grigoriou, "Ovarian cancer emerging subtypes: role of oxidative stress and fibrosis in tumour development and response to treatment," The International Journal of Biochemistry \& Cell Biology, vol. 45, no. 6, pp. 1092-1098, 2013.

[96] C. I. Cuzziol, M. M. U. Castanhole-Nunes, E. C. Pavarino, and E. M. Goloni-Bertollo, "MicroRNAs as regulators of VEGFA and NFE2L2 in cancer," Gene, vol. 759, article 144994, 2020.

[97] S. M. Acuna, L. M. Floeter-Winter, and S. M. Muxel, "MicroRNAs: biological regulators in pathogen-host interactions," Cell, vol. 9, no. 1, p. 113, 2020.

[98] A. Brozovic, G. E. Duran, Y. C. Wang, E. B. Francisco, and B. I. Sikic, "The mir-200 family differentially regulates sensitivity to paclitaxel and carboplatin in human ovarian carcinoma OVCAR-3 and MES-OV cells," Molecular Oncology, vol. 9, no. 8, pp. 1678-1693, 2015.

[99] B. Mateescu, L. Batista, M. Cardon et al., "mir-141 and mir200a act on ovarian tumorigenesis by controlling oxidative stress response," Nature Medicine, vol. 17, no. 12, pp. 16271635, 2011.

[100] S. Zhao, L. Cheng, Y. Shi, J. Li, Q. Yun, and H. Yang, "MIEF2 reprograms lipid metabolism to drive progression of ovarian cancer through ROS/AKT/mTOR signaling pathway," Cell Death \& Disease, vol. 12, no. 1, 2021.

[101] X. Deng, N. Lin, J. Fu et al., "The Nrf2/PGC1 $\alpha$ Pathway Regulates Antioxidant and Proteasomal Activity to Alter Cisplatin Sensitivity in Ovarian Cancer," Oxidative Medicine and Cellular Longevity, vol. 2020, Article ID 4830418, 15 pages, 2020.

[102] H. Y. Yang, J. X. Shen, Y. Wang, Y. Liu, D. Y. Shen, and S. Quan, "Tankyrase promotes aerobic glycolysis and proliferation of ovarian cancer through activation of Wnt/betacatenin signaling," BioMed Research International, vol. 2019, Article ID 2686340, 2019.

[103] A. El-Sehemy, A. C. Chang, A. K. Azad et al., "Notch activation augments nitric oxide/soluble guanylyl cyclase signaling in immortalized ovarian surface epithelial cells and ovarian cancer cells," Cellular Signalling, vol. 25, no. 12, pp. 27802787, 2013.

[104] X. Wu, L. Y. Han, X. X. Zhang, and L. Wang, "The study of Nrf2 signaling pathway in ovarian cancer," Critical Reviews in Eukaryotic Gene Expression, vol. 28, no. 4, pp. 329-336, 2018.

[105] S. K. Niture, J. W. Kaspar, J. Shen, and A. K. Jaiswal, "Nrf2 signaling and cell survival," Toxicology and Applied Pharmacology, vol. 244, no. 1, pp. 37-42, 2010.

[106] N. F. Villeneuve, A. Lau, and D. D. Zhang, "Regulation of the Nrf2-Keap1 antioxidant response by the ubiquitin proteasome system: an insight into cullin-ring ubiquitin ligases," Antioxidants \& Redox Signaling, vol. 13, no. 11, pp. 1699$1712,2010$.

[107] D. Li, X. Hong, F. Zhao, X. Ci, and S. Zhang, "Targeting Nrf2 may reverse the drug resistance in ovarian cancer," Cancer Cell International, vol. 21, no. 1, 2021.
[108] I. Ganan-Gomez, Y. Wei, H. Yang, M. C. Boyano-Adanez, and G. Garcia-Manero, "Oncogenic functions of the transcription factor Nrf2," Free Radical Biology \& Medicine, vol. 65, pp. 750-764, 2013.

[109] H. S. Khalil, A. Goltsov, S. P. Langdon, D. J. Harrison, J. Bown, and Y. Deeni, "Quantitative analysis of Nrf2 pathway reveals key elements of the regulatory circuits underlying antioxidant response and proliferation of ovarian cancer cells," Journal of Biotechnology, vol. 202, pp. 12-30, 2015.

[110] R. Sirota, D. Gibson, and R. Kohen, "The role of the catecholic and the electrophilic moieties of caffeic acid in Nrf2/Keap1 pathway activation in ovarian carcinoma cell lines," Redox Biology, vol. 4, pp. 48-59, 2015.

[111] F. Lang, J. Qu, H. Yin et al., "Apoptotic cell death induced by Z-ligustilidein human ovarian cancer cells and role of Nrf2," Food and Chemical Toxicology, vol. 121, pp. 631-638, 2018.

[112] M. G. van der Wijst, C. Huisman, A. Mposhi, G. Roelfes, and M. G. Rots, "Targeting Nrf2 in healthy and malignant ovarian epithelial cells: protection versus promotion," Molecular Oncology, vol. 9, no. 7, pp. 1259-1273, 2015.

[113] M. H. Xia, X. Y. Yan, L. Zhou et al., "P62 suppressed Vk3induced oxidative damage through Keap1/Nrf2 pathway in human ovarian cancer cells," Journal of Cancer, vol. 11, no. 6, pp. 1299-1307, 2020.

[114] N. Liu, X. Lin, and C. Huang, "Activation of the reverse transsulfuration pathway through NRF2/CBS confers erastininduced ferroptosis resistance," British Journal of Cancer, vol. 122, no. 2, pp. 279-292, 2020.

[115] M. Xia, H. Yu, S. Gu et al., "P62/Sqstm1 is involved in cisplatin resistance in human ovarian cancer cells via the Keap1-Nrf2-Are system," International Journal of Oncology, vol. 45, no. 6, pp. 2341-2348, 2014.

[116] P. A. Konstantinopoulos, D. Spentzos, E. Fountzilas et al., "Keap1 mutations and Nrf2 pathway activation in epithelial ovarian cancer," Cancer Research, vol. 71, no. 15, pp. 50815089, 2011.

[117] J. Wu, L. Zhang, H. Li, S. Wu, and Z. Liu, "Nrf2 induced cisplatin resistance in ovarian cancer by promoting $\mathrm{Cd} 99$ expression," Biochemical and Biophysical Research Communications, vol. 518, no. 4, pp. 698-705, 2019.

[118] H.-y. Cho, K. Kim, Y.-B. Kim, H. Kim, and J. H. No, "Expression patterns of Nrf2 and Keap1 in ovarian cancer cells and their prognostic role in disease recurrence and patient survival," International Journal of Gynecological Cancer, vol. 27, no. 3, pp. 412-419, 2017.

[119] A. U. R. Aziz, S. Farid, K. Qin, H. Wang, and B. Liu, "PIM kinases and their relevance to the PI3K/AKT/mTOR pathway in the regulation of ovarian cancer," Biomolecules, vol. 8, no. 1, p. 7, 2018.

[120] Z. C. Dobbin and C. N. Landen, "The importance of the $\mathrm{PI} 3 \mathrm{~K} / \mathrm{AKT} / \mathrm{mTOR}$ pathway in the progression of ovarian cancer," International Journal of Molecular Sciences, vol. 14, no. 4, pp. 8213-8227, 2013.

[121] M. K. Ediriweera, K. H. Tennekoon, and S. R. Samarakoon, "Role of the PI3K/AKT/mTOR signaling pathway in ovarian cancer: biological and therapeutic significance," Seminars in Cancer Biology, vol. 59, pp. 147-160, 2019.

[122] S. Mabuchi, H. Kuroda, R. Takahashi, and T. Sasano, "The $\mathrm{PI} 3 \mathrm{~K} / \mathrm{AKT} / \mathrm{mTOR}$ pathway as a therapeutic target in ovarian cancer," Gynecologic Oncology, vol. 137, no. 1, pp. 173-179, 2015. 
[123] K. Sakamoto, K. Iwasaki, H. Sugiyama, and Y. Tsuji, "Role of the tumor suppressor PTEN in antioxidant responsive element-mediated transcription and associated histone modifications," Molecular Biology of the Cell, vol. 20, no. 6, pp. 1606-1617, 2009.

[124] J. van der Reest, S. Lilla, L. Zheng, S. Zanivan, and E. Gottlieb, "Proteome-wide analysis of cysteine oxidation reveals metabolic sensitivity to redox stress," Nature Communications, vol. 9, no. 1, 2018.

[125] W. S. Wu, "The signaling mechanism of ROS in tumor progression," Cancer and Metastasis Reviews, vol. 25, no. 4, pp. 695-705, 2007.

[126] Y. K. Lee and N. H. Park, "Prognostic value and clinicopathological significance of $p 53$ and PTEN in epithelial ovarian cancers," Gynecologic Oncology, vol. 112, no. 3, pp. 475-480, 2009.

[127] L. Z. Liu, X. W. Hu, C. Xia et al., "Reactive oxygen species regulate epidermal growth factor-induced vascular endothelial growth factor and hypoxia-inducible factor- $1 \alpha$ expression through activation of AKT and P70S6K1 in human ovarian cancer cells," Free Radical Biology and Medicine, vol. 41, no. 10, pp. 1521-1533, 2006.

[128] K. Engels, S. K. Knauer, S. Loibl et al., "No signaling confers cytoprotectivity through the survivin network in ovarian carcinomas," Cancer Research, vol. 68, no. 13, pp. 5159-5166, 2008.

[129] H. L. Yang, R. W. Lin, P. Rajendran et al., “Antrodia salmonea-induced oxidative stress abrogates Her-2 signaling cascade and enhanced apoptosis in ovarian carcinoma cells," Journal of Cellular Physiology, vol. 234, no. 3, pp. 3029-3042, 2019.

[130] C. E. Ford, C. Henry, E. Llamosas, A. Djordjevic, and N. Hacker, "Wnt signalling in gynaecological cancers: a future target for personalised medicine?," Gynecologic Oncology, vol. 140, no. 2, pp. 345-351, 2016.

[131] A. McMellen, E. R. Woodruff, B. R. Corr, B. G. Bitler, and M. R. Moroney, "Wnt signaling in gynecologic malignancies," International Journal of Molecular Sciences, vol. 21, no. 12, p. 4272, 2020.

[132] V. H. L. Nguyen, R. Hough, S. Bernaudo, and C. Peng, "Wnt/ $\beta$-catenin signalling in ovarian cancer: insights into its hyperactivation and function in tumorigenesis," Journal of Ovarian Research, vol. 12, no. 1, 2019.

[133] R. C. Arend, A. I. Londono-Joshi, J. M. Straughn Jr., and D. J. Buchsbaum, "The Wnt/ $\beta$-catenin pathway in ovarian cancer: A review," Gynecologic Oncology, vol. 131, no. 3, pp. 772-779, 2013.

[134] W. N. Goldsberry, S. Meza-Perez, A. I. Londoño et al., "Inhibiting Wnt ligand production for improved immune recognition in the ovarian tumor microenvironment," Cancers, vol. 12, no. 3, p. 766, 2020.

[135] I. Betella, W. J. Turbitt, T. Szul et al., "Wnt signaling modulator Dkk1 as an immunotherapeutic target in ovarian cancer," Gynecologic Oncology, vol. 157, no. 3, pp. 765-774, 2020.

[136] Y. Wu, S. Antony, J. L. Meitzler, and J. H. Doroshow, "Molecular mechanisms underlying chronic inflammation-associated cancers," Cancer Letters, vol. 345, no. 2, pp. 164-173, 2014.

[137] M. Teeuwssen and R. Fodde, "Wnt signaling in ovarian cancer stemness, EMT, and therapy resistance," Journal of Clinical Medicine, vol. 8, no. 10, 2019.

[138] A. Vallee and Y. Lecarpentier, "Crosstalk between peroxisome proliferator-activated receptor gamma and the canoni- cal WNT/ $\beta$-Catenin pathway in chronic inflammation and oxidative stress during Carcinogenesis," Frontiers in Immunology, vol. 9, 2018.

[139] X. Yan, T. Lyu, N. Jia, Y. Yu, K. Hua, and W. Feng, "Huaier aqueous extract inhibits ovarian cancer cell motility via the AKT/GSK3 $\beta / \beta$-Catenin pathway," PLoS One, vol. 8, no. 5, article e63731, 2013.

[140] L. N. Lili, L. V. Matyunina, L. D. Walker, S. L. Wells, B. B. Benigno, and J. F. McDonald, "Molecular profiling supports the role of epithelial-to-mesenchymal transition (EMT) in ovarian cancer metastasis," Journal of Ovarian Research, vol. 6, no. 1, 2013.

[141] B. Davidson, C. G. Trope, and R. Reich, "Epithelial-mesenchymal transition in ovarian carcinoma," Frontiers in Oncology, vol. 2, 2012.

[142] J. Wen, Z. Zhao, L. Huang, L. Wang, Y. Miao, and J. Wu, "IL-8 promotes cell migration through regulating EMT by activating the Wnt/ $\beta$-catenin pathway in ovarian cancer," Journal of Cellular and Molecular Medicine, vol. 24, no. 2, pp. 1588-1598, 2020.

[143] S. Raghavan, P. Mehta, Y. Xie, Y. L. Lei, and G. Mehta, “Ovarian cancer stem cells and macrophages reciprocally interact through the Wnt pathway to promote pro-tumoral and malignant phenotypes in 3D engineered microenvironments," Journal for ImmunoTherapy of Cancer, vol. 7, no. 1, 2019.

[144] X. Ruan, A. Liu, M. Zhong et al., "Silencing LGR6 Attenuates Stemness and Chemoresistance via Inhibiting $\mathrm{Wnt} / \beta$ Catenin Signaling in Ovarian Cancer," Molecular Therapy Oncolytics, vol. 14, pp. 94-106, 2019.

[145] L. al-Alem and T. E. Curry Jr., "Ovarian cancer: involvement of the matrix metalloproteinases," Reproduction, vol. 150, no. 2, pp. R55-R64, 2015.

[146] J. A. Wall, S. Meza-Perez, C. B. Scalise et al., "Manipulating the $\mathrm{Wnt} / \beta$-catenin signaling pathway to promote antitumor immune infiltration into the TME to sensitize ovarian cancer to ICB therapy," Gynecologic Oncology, vol. 160, no. 1, pp. 285-294, 2021.

[147] S. H. Barghout, N. Zepeda, Z. Xu, H. Steed, C. H. Lee, and Y. Fu, "Elevated $\beta$-catenin activity contributes to carboplatin resistance in A2780cp ovarian cancer cells," Biochemical and Biophysical Research Communications, vol. 468, no. 1-2, pp. 173-178, 2015.

[148] Z. Sun, S. Xu, Q. Cai et al., "Wnt/ $\beta$-catenin agonist BIO alleviates cisplatin-induced nephrotoxicity without compromising its efficacy of anti-proliferation in ovarian cancer," Life Sciences, vol. 263, article 118672, 2020.

[149] J. W. Groeneweg, R. Foster, W. B. Growdon, R. H. Verheijen, and B. R. Rueda, "Notch signaling in serous ovarian cancer," Journal of Ovarian Research, vol. 7, no. 1, 2014.

[150] M. Akbarzadeh, S. Akbarzadeh, and M. Majidinia, “Targeting Notch signaling pathway as an effective strategy in overcoming drug resistance in ovarian cancer," Pathology - Research and Practice, vol. 216, no. 11, article 153158, 2020.

[151] F. Silva, A. Felix, and J. Serpa, "Functional redundancy of the Notch pathway in ovarian cancer cell lines," Oncology Letters, vol. 12, no. 4, pp. 2686-2691, 2016.

[152] Q. Xie, Z. Cheng, X. Chen, C. G. Lobe, and J. Liu, "The role of Notch signalling in ovarian angiogenesis," Journal of Ovarian Research, vol. 10, no. 1, 2017.

[153] T. J. Tzeng, L. Cao, Y. Fu, H. Zeng, and W. H. Cheng, "Methylseleninic acid sensitizes Notch3-activated Ovca429 
ovarian cancer cells to carboplatin," PLoS One, vol. 9, no. 7, article e101664, 2014.

[154] S. Bocchicchio, M. Tesone, and G. Irusta, "Convergence of Wnt and Notch signaling controls ovarian cancer cell survival," Journal of Cellular Physiology, vol. 234, no. 12, pp. 22130-22143, 2019.

[155] K. Canté-Barrett, L. Holtzer, H. van Ooijen et al., "A molecular test for quantifying functional Notch signaling pathway activity in human cancer," Cancers, vol. 12, no. 11, 2020.

[156] L. Silwal-Pandit, A. Langerod, and A. L. Borresen-Dale, "TP53Mutations in breast and ovarian cancer," Cold Spring Harbor Perspectives in Medicine, vol. 7, no. 1, 2017.

[157] M. Nakamura, T. Obata, T. Daikoku, and H. Fujiwara, "The association and significance of P53 in gynecologic cancers: the potential of targeted therapy," International Journal of Molecular Sciences, vol. 20, no. 21, 2019.

[158] O. Kim, E. Y. Park, D. L. Klinkebiel et al., "In vivo modeling of metastatic human high-grade serous ovarian cancer in mice," PLoS Genetics, vol. 16, no. 6, article e1008808, 2020.

[159] M. Cordani, G. Butera, R. Pacchiana et al., "Mutant P53associated molecular mechanisms of ROS regulation in cancer cells," Biomolecules, vol. 10, no. 3, p. 361, 2020.

[160] F. Mantovani, L. Collavin, and G. Del Sal, "Mutant P53 as a guardian of the cancer cell," Cell Death \& Differentiation, vol. 26, no. 2, pp. 199-212, 2019.

[161] X. Liu, L. Fan, C. Lu, S. Yin, and H. Hu, "Functional role of P53 in the regulation of chemical-induced oxidative stress," Oxidative Medicine and Cellular Longevity, vol. 2020, Article ID 6039769, 10 pages, 2020.

[162] D. P. Bai, X. F. Zhang, G. L. Zhang, Y. F. Huang, and S. Gurunathan, "Zinc oxide nanoparticles induce apoptosis and autophagy in human ovarian cancer cells," International Journal of Nanomedicine, vol. 12, pp. 6521-6535, 2017.

[163] A. K. Maiti, "Gene network analysis of oxidative stressmediated drug sensitivity in resistant ovarian carcinoma cells," The Pharmacogenomics Journal, vol. 10, no. 2, pp. 94-104, 2010.

[164] Y. A. Suh, S. M. Post, A. C. Elizondo-Fraire et al., "Multiple stress signals activate mutant p53In vivo," Cancer Research, vol. 71, no. 23, pp. 7168-7175, 2011.

[165] A. Padmanabhan, M. Kaushik, R. Niranjan, J. S. Richards, B. Ebright, and G. D. Venkatasubbu, "Zinc oxide nanoparticles induce oxidative and proteotoxic stress in ovarian cancer cells and trigger apoptosis independent of P53-mutation status," Applied Surface Science, vol. 487, pp. 807-818, 2019.

[166] K. P. Zeligs, M. K. Neuman, and C. M. Annunziata, "Molecular pathways: the balance between cancer and the immune system challenges the therapeutic specificity of targeting nuclear factor- $\mathrm{Kb}$ signaling for cancer treatment," Clinical Cancer Research, vol. 22, no. 17, pp. 4302-4308, 2016.

[167] K. L. White, D. N. Rider, K. R. Kalli, K. L. Knutson, G. P. Jarvik, and E. L. Goode, "Genomics of the NF- $\kappa$ B signaling pathway: hypothesized role in ovarian cancer," Cancer Causes Control, vol. 22, no. 5, pp. 785-801, 2011.

[168] Y. R. Puar, M. K. Shanmugam, L. Fan, F. Arfuso, G. Sethi, and V. Tergaonkar, "Evidence for the involvement of the master transcription factor NF- $\kappa \mathrm{B}$ in cancer initiation and progression," Biomedicines, vol. 6, no. 3, p. 82, 2018.

[169] B. S. Harrington and C. M. Annunziata, "NF- $\kappa$ B signaling in ovarian cancer," Cancers, vol. 11, no. 8, 2019.

[170] E. G. Kleinschmidt, N. L. G. Miller, D. Ozmadenci et al., "Rgnef promotes ovarian tumor progression and confers pro- tection from oxidative stress," Oncogene, vol. 38, no. 36, pp. 6323-6337, 2019.

[171] K. K. Kiningham, Y. Xu, C. Daosukho, B. Popova, and D. K. S. T. Clair, "Nuclear factor $\kappa \mathrm{B}$-dependent mechanisms coordinate the synergistic effect of PMA and cytokines on the induction of superoxide dismutase 2," The Biochemical Journal, vol. 353, no. 1, pp. 147-156, 2001.

[172] K. Mortezaee, M. Najafi, B. Farhood, A. Ahmadi, D. Shabeeb, and A. E. Musa, "NF- $\kappa \mathrm{B}$ targeting for overcoming tumor resistance and normal tissues toxicity," Journal of Cellular Physiology, vol. 234, no. 10, pp. 17187-17204, 2019.

[173] G. Gloire and J. Piette, "Redox regulation of nuclear posttranslational modifications during NF- $\kappa \mathrm{B}$ activation," Antioxidants \& Redox Signaling, vol. 11, no. 9, pp. 2209-2222, 2009.

[174] H. Pei, Y. Yang, L. Cui et al., "Bisdemethoxycurcumin inhibits ovarian cancer via reducing oxidative stress mediated MMPs expressions," Scientific Reports, vol. 6, no. 1, article 28773, 2016.

[175] M. Buelna-Chontal and C. Zazueta, "Redox activation of Nrf2 \& NF- $\kappa$ B: a double end sword?," Cellular Signalling, vol. 25, no. 12, pp. 2548-2557, 2013.

[176] L. M. Seeber, N. Horrée, M. A. Vooijs et al., "The role of hypoxia inducible factor-1alpha in gynecological cancer," Critical Reviews in Oncology/Hematology, vol. 78, no. 3, pp. 173-184, 2011.

[177] G. L. Semenza, "HIF-1 and tumor progression: pathophysiology and therapeutics," Trends in Molecular Medicine, vol. 8, no. 4, pp. S62-S67, 2002.

[178] A. Galanis, A. Pappa, A. Giannakakis, E. Lanitis, D. Dangaj, and R. Sandaltzopoulos, "Reactive oxygen species and HIF-1 signalling in cancer," Cancer Letters, vol. 266, no. 1, pp. 1220, 2008.

[179] Q. Ao, W. Su, S. Guo, L. Cai, and L. Huang, "SENP1 desensitizes hypoxic ovarian cancer cells to cisplatin by up- regulating HIF-1 $\alpha$," Scientific Reports, vol. 5, no. 1, article 16396, 2015.

[180] P. Zhang, Y. Liu, Y. Feng, and S. Gao, "Snail gene inhibited by hypoxia-inducible factor $1 \alpha$ (HIF- $1 \alpha$ ) in epithelial ovarian cancer," International Journal of Immunopathology and Pharmacology, vol. 29, no. 3, pp. 364-375, 2016.

[181] Y. Wang, J. Ma, H. Shen et al., "Reactive oxygen species promote ovarian cancer progression via the HIF- $1 \alpha /$ Lox/E-cadherin pathway," Oncology Reports, vol. 32, no. 5, pp. 2150 2158, 2014.

[182] T. Zhao, C. Zhao, Y. Zhou, J. Zheng, S. Gao, and Y. Lu, "HIF$1 \alpha$ binding to AEG-1 promoter induced upregulated AEG-1 expression associated with metastasis in ovarian cancer," Cancer Medicine, vol. 6, no. 5, pp. 1072-1081, 2017.

[183] T. Lu, J. Tang, B. Shrestha et al., "Up-regulation of hypoxiainducible factor antisense as a novel approach to treat ovarian cancer," Theranostics, vol. 10, no. 15, pp. 6959-6976, 2020.

[184] D. Nair, E. Rådestad, P. Khalkar et al., "Methylseleninic acid sensitizes ovarian cancer cells to T-cell mediated killing by decreasing PDL1 and VEGF levels," Frontiers in Oncology, vol. 8, 2018.

[185] L. Huang, Q. Ao, Q. Zhang et al., "Hypoxia induced paclitaxel resistance in human ovarian cancers via hypoxia-inducible factor $1 \alpha$," Journal of Cancer Research and Clinical Oncology, vol. 136, no. 3, pp. 447-456, 2010.

[186] A. Lindgren, M. Anttila, S. Rautiainen et al., "Dynamic contrast-enhanced perfusion parameters in ovarian cancer: 
good accuracy in identifying high HIF- $1 \alpha$ expression," PLoS One, vol. 14, no. 8, article e0221340, 2019.

[187] Y. Jiang, C. Wang, and S. Zhou, "Targeting tumor microenvironment in ovarian cancer: premise and promise," Biochimica et Biophysica Acta (BBA) - Reviews on Cancer, vol. 1873, no. 2, article 188361, 2020.

[188] T. Worzfeld, E. Pogge von Strandmann, M. Huber et al., “The unique molecular and cellular microenvironment of ovarian cancer," Frontiers in Oncology, vol. 7, 2017.

[189] B. Zhang, F. Chen, Q. Xu et al., "Revisiting ovarian cancer microenvironment: a friend or a foe?," Protein Cell, vol. 9, no. 8, pp. 674-692, 2018.

[190] N. Nakao, T. Kurokawa, T. Nonami, G. Tumurkhuu, N. Koide, and T. Yokochi, "Hydrogen peroxide induces the production of tumor necrosis factor- $\alpha$ in RAW 264.7 macrophage cells via activation of P38 and stress-activated protein kinase," Innate Immunity, vol. 14, no. 3, pp. 190-196, 2008.

[191] H. Blaser, C. Dostert, T. W. Mak, and D. Brenner, "TNF and ROS crosstalk in inflammation," Trends in Cell Biology, vol. 26, no. 4, pp. 249-261, 2016.

[192] M. Rasool, A. Malik, M. A. Basit Ashraf et al., "Evaluation of matrix metalloproteinases, cytokines and their potential role in the development of ovarian cancer," PLoS One, vol. 11, no. 11, article e0167149, 2016.

[193] J. M. Weiss, L. C. Davies, M. Karwan et al., "Itaconic acid mediates crosstalk between macrophage metabolism and peritoneal tumors," Journal of Clinical Investigation, vol. 128, no. 9, pp. 3794-3805, 2018.

[194] M. Klink, K. Jastrzembska, M. Nowak et al., "Ovarian cancer cells modulate human blood neutrophils response to ActivationIn vitro," Scandinavian Journal of Immunology, vol. 68, no. 3, pp. 328-336, 2008.

[195] M. Perego, V. A. Tyurin, Y. Y. Tyurina et al., "Reactivation of dormant tumor cells by modified lipids derived from stressactivated neutrophils," Science Translational Medicine, vol. 12, no. $572,2020$.

[196] Z. M. Zheng, H. L. Yang, Z. Z. Lai et al., "Myeloid-derived suppressor cells in obstetrical and gynecological diseases," American Journal of Reproductive Immunology, vol. 84, no. 2, article e13266, 2020.

[197] T. Baert, A. Vankerckhoven, M. Riva et al., "Myeloid derived suppressor cells: key drivers of immunosuppression in ovarian cancer," Frontiers in Immunology, vol. 10, 2019.

[198] K. Okla, A. Czerwonka, A. Wawruszak et al., "Clinical relevance and immunosuppressive pattern of circulating and infiltrating subsets of myeloid-derived suppressor cells (MDSCs) in epithelial ovarian cancer," Frontiers in Immunology, vol. 10, 2019.

[199] X. Li, J. Wang, W. Wu et al., "Myeloid-derived suppressor cells promote epithelial ovarian cancer cell stemness by inducing the CSF2/P-STAT3 signalling pathway," The FEBS Journal, vol. 287, no. 23, pp. 5218-5235, 2020.

[200] K. Ohl and K. Tenbrock, "Reactive oxygen species as regulators of MDSC-mediated immune suppression," Frontiers in Immunology, vol. 9, 2018.

[201] J. Wei, M. Zhang, and J. Zhou, "Myeloid-derived suppressor cells in major depression patients suppress T-cell responses through the production of reactive oxygen species," Psychiatry Research, vol. 228, no. 3, pp. 695-701, 2015.

[202] Y. Yang, A. V. Bazhin, J. Werner, and S. Karakhanova, "Reactive oxygen species in the immune system," International Reviews of Immunology, vol. 32, no. 3, pp. 249-270, 2013.
[203] S. Nagaraj, K. Gupta, V. Pisarev et al., "Altered recognition of antigen is a mechanism of Cd8+ T cell tolerance in cancer," Nature Medicine, vol. 13, no. 7, pp. 828-835, 2007.

[204] T. Maj, W. Wang, J. Crespo et al., "Oxidative stress controls regulatory $\mathrm{T}$ cell apoptosis and suppressor activity and $\mathrm{Pd}$ L1-blockade resistance in tumor," Nature Immunology, vol. 18, no. 12, pp. 1332-1341, 2017.

[205] F. Battisti, C. Napoletano, H. Rahimi Koshkaki et al., "Tumor-derived microvesicles modulate antigen crossprocessing via reactive oxygen species-mediated alkalinization of phagosomal compartment in dendritic cells," Frontiers in Immunology, vol. 8, 2017.

[206] M. Dionisi, C. de Archangelis, F. Battisti et al., "Tumorderived microvesicles enhance cross-processing ability of clinical grade dendritic cells," Frontiers in Immunology, vol. 9, 2018.

[207] J. Mikuła-Pietrasik, P. Uruski, S. Szubert et al., "Malignant ascites determine the transmesothelial invasion of ovarian cancer cells," The International Journal of Biochemistry \& Cell Biology, vol. 92, pp. 6-13, 2017.

[208] W. Yang, S. E. Toffa, J. W. Lohn, A. M. Seifalian, and M. C. Winslet, "Malignant ascites increases the antioxidant ability of human ovarian (SKOV-3) and gastric adenocarcinoma (KATO-III) cells," Gynecologic Oncology, vol. 96, no. 2, pp. 430-438, 2005.

[209] B. L. Worley, Y. S. Kim, J. Mardini et al., "GPx3 supports ovarian cancer progression by manipulating the extracellular redox environment," Redox Biology, vol. 25, article 101051, 2019.

[210] C. Klomsiri, L. A. C. Rogers, L. Soito et al., "Endosomal $\mathrm{H}_{2} \mathrm{O}_{2}$ production leads to localized cysteine sulfenic acid formation on proteins during lysophosphatidic acid-mediated cell signaling," Free Radical Biology and Medicine, vol. 71, pp. 49-60, 2014.

[211] J. A. Saunders, L. C. Rogers, C. Klomsiri, L. B. Poole, and L. W. Daniel, "Reactive oxygen species mediate lysophosphatidic acid induced signaling in ovarian cancer cells," Free Radical Biology and Medicine, vol. 49, no. 12, pp. 20582067, 2010.

[212] L. C. Rogers, R. R. Davis, N. Said, T. Hollis, and L. W. Daniel, "Blocking LPA-dependent signaling increases ovarian cancer cell death in response to chemotherapy," Redox Biology, vol. 15, pp. 380-386, 2018.

[213] C. Shao, F. Yang, S. Miao et al., "Role of hypoxia-induced exosomes in tumor biology," Molecular Cancer, vol. 17, no. 1, 2018.

[214] A. Rogalska, A. Gajek, M. Lukawska, I. Oszczapowicz, and A. Marczak, "Novel oxazolinoanthracyclines as tumor cell growth inhibitors-contribution of autophagy and apoptosis in solid tumor cells death," PLoS One, vol. 13, no. 7, article e0201296, 2018.

[215] H. Yang, R. M. Villani, H. Wang et al., "The role of cellular reactive oxygen species in cancer chemotherapy," Journal of Experimental \& Clinical Cancer Research, vol. 37, no. 1, 2018.

[216] F. Zhao, X. Hong, D. Li, Z. Wei, X. Ci, and S. Zhang, "Diosmetin induces apoptosis in ovarian cancer cells by activating reactive oxygen species and inhibiting the Nrf2 pathway," Medical Oncology, vol. 38, no. 5, 2021.

[217] G. AlBasher, A. A. AlKahtane, S. Alarifi et al., "Methotrexateinduced apoptosis in human ovarian adenocarcinoma SKOV-3 cells via ROS-mediated $\mathrm{Bax} / \mathrm{Bcl}-2-\mathrm{Cyt}-\mathrm{C}$ release 
cascading," OncoTargets and Therapy, vol. 12, pp. 21-30, 2019.

[218] D. Hou, Z. Liu, X. Xu et al., "Increased oxidative stress mediates the antitumor effect of PARP inhibition in ovarian cancer," Redox Biology, vol. 17, pp. 99-111, 2018.

[219] Z. Ai, Y. Lu, S. Qiu, and Z. Fan, "Overcoming cisplatin resistance of ovarian cancer cells by targeting HIF-1-regulated cancer metabolism," Cancer Letters, vol. 373, no. 1, pp. 3644, 2016.

[220] T. Ahmad and Y. J. Suzuki, "Juglone in oxidative stress and cell signaling," Antioxidants, vol. 8, no. 4, 2019.

[221] F. Fang, L. Z. Zhao, Q. Li et al., "Effects of juglone on oxidative stress and apoptosis of ovarian cancer SKOV3 cells," Chinese Journal of Pathophysiology, vol. 32, no. 1, pp. 156-159, 2016.

[222] M. A. Cucci, M. Grattarola, C. Dianzani et al., "Ailanthone increases oxidative stress in CDDP-resistant ovarian and bladder cancer cells by inhibiting of Nrf2 and YAP expression through a post- translational mechanism," Free Radical Biology and Medicine, vol. 150, pp. 125-135, 2020.

[223] R. Benot-Dominguez, M. G. Tupone, V. Castelli et al., "Olive leaf extract impairs mitochondria by pro-oxidant activity in MDA-MB-231 and OVCAR-3 cancer cells," Biomedicine \& Pharmacotherapy, vol. 134, article 111139, 2021.

[224] S. S. Taparia and A. Khanna, "Procyanidin-rich extract of natural cocoa powder causes ROS-mediated caspase-3 dependent apoptosis and reduction of pro-MMP-2 in epithelial ovarian carcinoma cell lines," Biomedicine \& Pharmacotherapy, vol. 83, pp. 130-140, 2016.

[225] M. Seino, M. Okada, K. Shibuya et al., "Differential contribution of ROS to resveratrol-induced cell death and loss of selfrenewal capacity of ovarian cancer stem cells," Anticancer Research, vol. 35, no. 1, pp. 85-96, 2015.

[226] T. H. Kim, J. H. Park, and J. S. Woo, "Resveratrol induces cell death through ROS-dependent downregulation of Notch1/Pten/Akt signaling in ovarian cancer cells," Molecular Medicine Reports, vol. 19, no. 4, pp. 3353-3360, 2019.

[227] J. Mikuła-Pietrasik, P. Sosińska, M. Murias et al., "High Potency of a Novel Resveratrol Derivative, 3,3',4,4'-Tetrahydroxy-trans- stilbene, against Ovarian Cancer Is Associated with an Oxidative Stress- Mediated Imbalance between DNA Damage Accumulation and Repair," Oxidative Medicine and Cellular Longevity, vol. 2015, Article ID 135691, 15 pages, 2015.

[228] R. Sahai, A. Bhattacharjee, V. N. Shukla et al., "Gedunin isolated from the mangrove plant Xylocarpus granatum exerts its anti-proliferative activity in ovarian cancer cells through G2/M-phase arrest and oxidative stress-mediated intrinsic apoptosis," Apoptosis, vol. 25, no. 7-8, pp. 481-499, 2020.

[229] T. C. Hsieh and J. M. Wu, "Suppression of proliferation and oxidative stress by extracts of Ganoderma lucidum in the ovarian cancer cell line OVCAR-3," International Journal of Molecular Medicine, vol. 28, no. 6, pp. 1065-1069, 2011.

[230] S. S. Liu and Y. Q. Zhou, "Research progress of nanotechnology in ovarian cancer," Medical Review, vol. 22, no. 5, pp. 893-896, 2016.

[231] I. Santos, C. Ramos, C. Mendes et al., "Targeting glutathione and cystathionine $B$-synthase in ovarian cancer treatment by selenium-chrysin polyurea dendrimer nanoformulation," Nutrients, vol. 11, no. 10, 2019.
[232] W. Niu, J. Wang, Q. Wang, and J. Shen, "Celastrol loaded nanoparticles with ROS-response and ROS-inducer for the treatment of ovarian cancer," Frontiers in Chemistry, vol. 8, article 574614, 2020.

[233] E. Elejalde, M. C. Villaran, and R. M. Alonso, "Grape polyphenols supplementation for exercise-induced oxidative stress," Journal of the International Society of Sports Nutrition, vol. 18, no. 1, p. 3, 2021

[234] P. Poprac, K. Jomova, M. Simunkova, V. Kollar, C. J. Rhodes, and M. Valko, "Targeting free radicals in oxidative stressrelated human diseases," Trends in Pharmacological Sciences, vol. 38, no. 7, pp. 592-607, 2017.

[235] T. T. Huang, E. J. Lampert, C. Coots, and J. M. Lee, “Targeting the PI3K pathway and DNA damage response as a therapeutic strategy in ovarian cancer," Cancer Treatment Reviews, vol. 86, article 102021, 2020.

[236] S. Mabuchi, T. Hisamatsu, and T. Kimura, "Targeting mTOR signaling pathway in ovarian cancer," Current Medicinal Chemistry, vol. 18, no. 19, pp. 2960-2968, 2011.

[237] J. Wang, L. Jin, X. Li et al., "Gossypol induces apoptosis in ovarian cancer cells through oxidative stress," Molecular BioSystems, vol. 9, no. 6, pp. 1489-1497, 2013.

[238] D. Hou, G. Xu, C. Zhang et al., "Berberine induces oxidative DNA damage and impairs homologous recombination repair in ovarian cancer cells to confer increased sensitivity to PARP inhibition," Cell Death \& Disease, vol. 8, no. 10, article e3070, 2017.

[239] R. Li, J. Xiao, S. Tang et al., "Cucurbitacin I induces apoptosis in ovarian cancer cells through oxidative stress and the P190b-Rac1 signaling axis," Molecular Medicine Reports, vol. 22, no. 3, pp. 2545-2550, 2020.

[240] A. T. Mbemi, J. N. Sims, C. G. Yedjou, F. K. Noubissi, C. R. Gomez, and P. B. Tchounwou, "Vernonia calvoana shows promise towards the treatment of ovarian cancer," International Journal of Molecular Sciences, vol. 21, no. 12, 2020.

[241] Z. Tavsan and H. A. Kayali, "Flavonoids showed anticancer effects on the ovarian cancer cells: involvement of reactive oxygen species, apoptosis, cell cycle and invasion," Biomedicine \& Pharmacotherapy, vol. 116, article 109004, 2019.

[242] Y. Y. Wang, Y. K. Chen, S. C. Hu et al., "Cyt-Rx20 inhibits ovarian cancer cells in vitro and in vivo through oxidative stress-induced DNA damage and cell apoptosis," Cancer Chemotherapy and Pharmacology, vol. 79, no. 6, pp. 1129-1140, 2017.

[243] S. Park, W. Lim, W. Jeong, F. W. Bazer, D. Lee, and G. Song, "Sideroxylin (Callistemon lanceolatus) suppressed cell proliferation and increased apoptosis in ovarian cancer cells accompanied by mitochondrial dysfunction, the generation of reactive oxygen species, and an increase of lipid peroxidation," Journal of Cellular Physiology, vol. 233, no. 11, pp. 8597-8604, 2018.

[244] J. Xue, R. Li, X. Zhao et al., "Morusin induces paraptosis-like cell death through mitochondrial calcium overload and dysfunction in epithelial ovarian cancer," Chemico-Biological Interactions, vol. 283, pp. 59-74, 2018. 